\title{
Ion-dispersion and rapid electron fluctuations in the cusp: a case study
}

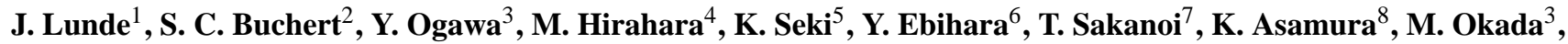 \\ T. Raita ${ }^{9}$, and I. Häggström ${ }^{10}$ \\ ${ }^{1}$ Department of Physics and Technology, University of Troms $\varnothing$, Norway \\ ${ }^{2}$ Swedish Institute of Space Physics, University of Uppsala, Sweden \\ ${ }^{3}$ National Institute of Polar Research (NIPR), Tokyo, Japan \\ ${ }^{4}$ Department of Earth and Planetary Science, University of Tokyo, Japan \\ ${ }^{5}$ STEL, Nagoya University, Japan \\ ${ }^{6}$ IAR, Nagoya University, Japan \\ ${ }^{7}$ PPARC, Tohoku University, Japan \\ ${ }^{8}$ ISAS/JAXA, Sagamihara, Japan \\ ${ }^{9}$ Sodankylä Geophysical Observatory, University of Oulu, Finland \\ ${ }^{10}$ EISCAT Scientific Association, Kiruna, Sweden
}

Received: 3 December 2007 - Revised: 14 April 2008 - Accepted: 11 July 2008 - Published: 20 August 2008

\begin{abstract}
We present results from co-ordinated measurements with the low altitude REIMEI satellite and the ESR (EISCAT Svalbard Radar), together with other ground-based instruments carried out in February 2006. The results mainly relate to the dayside cusp where clear signatures of so-called ion-dispersion are seen in the satellite data. The cusp iondispersion is important for helping to understand the temporal and spatial structure of magnetopause reconnection. Whenever a satellite crosses boundaries of flux tubes or convection cells, cusp structures such as ion-dispersion will always be encountered. In our case we observed 3 distinct steps in the ion energy, but it includes at least 2 more steps as well, which we interpret as temporal features in relation to pulsed reconnection at the magnetopause. In addition, fast variations of the electron flux and energy occurring during these events have been studied in detail. The variations of the electron population, if interpreted as structures crossed by the REIMEI satellite, would map near the magnetopause to similar features as observed previously with the Cluster satellites. These were explained as Alfvén waves originating from an X-line of magnetic reconnection.
\end{abstract}

Keywords. Ionosphere (Particle precipitation; Plasma convection; Polar ionosphere)

Correspondence to: J. Lunde

(june.lunde@ phys.uit.no)

\section{Introduction}

A change in the energy distributions of precipitating ions with latitude is known as ion-dispersion (Reiff et al., 1977). In the cusp, which is believed to be the main place of transport of plasma into the magnetosphere, such sudden changes in the energy of the downward precipitating ions from the magnetosheath occur regularly. Subsequently, distinctive structures are generated. This enables us to study the tempo$\mathrm{ral} / \mathrm{spatial}$ nature of reconnection at the magnetopause (Trattner et al., 2005).

It is well established by previous satellite observations that magnetosheath plasma can penetrate down to rather low altitudes at relatively high magnetic latitudes on the dayside of the earth (Heikkila and Winningham, 1971; Frank and Ackerson, 1971). This is believed to be a direct result of magnetosheath plasma entry through the dayside polar cusp (Frank, 1971). The cusp plasma thus consists of low energy ions $(50 \mathrm{eV}-3 \mathrm{keV})$ and an increased electron flux below a few hundreds eV (Escoubet et al., 2006). The low energy ions and electrons are of magnetosheath origin and the cusp region, depending on the Interplanetary Magnetic Field (IMF) conditions, can be found in the range from $73^{\circ}$ to $80^{\circ}$ magnetic latitude and located near magnetic noon between 10:30-13:30 MLT (Newell and Meng, 1988). However, despite the emphasis of low energy particles, it should be mentioned that cusp energetic particle (CEP) events have also been observed (Chen and Fritz, 2005). 
Dayside (sub-solar) reconnection during southward IMF conditions, $B_{z}<0$, will influence the ion-energy-dispersion in the cusp precipitation in such a way that the ion energy decreases with increasing magnetic latitude. During joint action of magnetic tension and shocked solar wind flow, these newly opened field lines from the dayside reconnection will convect poleward, away from the reconnection point, and the associated convection electric field will act as a "velocity filter" on particles from the injection point to the observation point, causing lower energy particles to arrive at successively higher latitudes (e.g. Smith and Lockwood, 1996). This "velocity filter" effect was first predicted by Rosenbauer et al. (1975) and first observed by Shelley et al. (1976) which reported energy dispersion in the low-altitude cusp. Accordingly, an ion-dispersion observed by a spacecraft crossing the polar cusp is a typical signature of reconnection (Escoubet et al., 2006). Thus the high energy ions from the magnetosheath that enter the cusp will then be observed close to the first open field line, while the low energy ones, which take longer time to reach the ionosphere, will be detected further away from it. However, as Reiff et al. (1977) demonstrated, the energy dispersion of cusp particles as a function of latitude depends on the mechanisms for injection of solar wind particles at the dayside magnetospheric cusp. From this, proposed mechanisms such as dayside magnetic merging of the geomagnetic and interplanetary magnetic fields (Frank, 1971) and wave-induced diffusion of particles across the magnetopause onto geomagnetic field lines (Heikkila, 1972), will produce different latitudinal distributions of particles penetrating to the low-altitude cusp. The characteristic energy decreases with increasing latitudinal distance from the last closed field line for the magnetic merging while the opposite yield for the cross field diffusion, as the characteristic energy increases with increasing latitudinal distance from the last closed field lines. Furthermore, ion-dispersion provides information about the reconnection process. For a steady rate of reconnection (fully continuous reconnection) at the magnetopause, continuous latitudinal energy dispersion (monotonic dispersion) of downward precipitating ions should be shown on these open field lines. Even so, the dispersion does not always vary smoothly with invariant latitude. Sudden changes in the cusp ion-dispersion and variations in the flux result in more complex structures, often observed as "stepped" or "staircase" cusp ion signatures and also known as cusp structured ion-energy-dispersion. The existence of these signatures have been predicted by Cowley et al. (1991) and Smith et al. (1992), based on a model by Cowley and Lockwood (1992) on how ionospheric convection is excited. This is in accordance with the so-called pulsating cusp model (e.g. Lockwood and Smith, 1989; Smith and Lockwood, 1990), where cusp steps are the result of changes in the reconnection rate at the magnetopause. This change creates neighbouring flux tubes in the cusp with different time histories since reconnection and the cusp precipitation between the steps are the result of pulses of enhanced magnetopause reconnection. Consequently, these steps occur for periods of little or no reconnection between the pulses.

In general, the shape of the ion-dispersion is dependent on the trajectory of the observing satellite with respect to the open closed boundary (OCB) as well as the convection velocity and the reconnection rate. In 1994, a cusp ion-dispersion signature caused by pulsed magnetopause reconnection was predicted for low- and mid-altitude satellites by Lockwood and Smith (1994). Using the condition of pulsed reconnection from an extended X-line, a model by Lockwood and Davis (1996) predicts how the structured cusp ion-dispersion should appear; stepped ion-dispersion for a meridional pass and sawtooth ion-dispersion for a longitudinal pass. From this, they show that the signatures for the same reconnection conditions depend on the angle which the satellite traverses the OCB. Additionally, Lockwood et al. (1998) predicts that pulsed reconnection will produce only the sawtooth signatures at middle- and high altitudes. Later on, Morley and Lockwood (2003) show by modelling that the forms of the ion-dispersion signatures also depend on the reconnection rate and the associated convection velocity, as is the overall boundary drift. As for the satellite velocity relative to the convection velocity of the cusp structure, the following where found: i) if the convection velocity is much greater than the satellite velocity a sawtooth signature is observed, ii) if the convection velocity is smaller than the satellite velocity a stepped signature is observed and finally iii) if the satellite stays at the same newly opened field line while moving poleward with the field lines, a smooth steady-state dispersion will be seen. Newell and Meng (1991) reported the first observation of stepped ion-energy-dispersion, then Escoubet et al. (1992), Lockwood et al. (1993a) and more thereafter while sawtooth ion-dispersion has been reported by Pinnock et al. (1995), Lockwood et al. (2001) and Trattner et al. (2003).

Large scale cusp structures could either be temporal or spatial, or a combination, reflecting the dayside reconnection rate and location. In general, temporal variations are related to the reconnection rate while the spatial variations are related to the reconnection location as global ionospheric convection patterns created by magnetic merging. The debate on whether the dayside reconnection is quasi-steady/quasicontinuous (spatial) or transient/intermittent (temporal) is still ongoing. The issues may be summarised as follows:

1. If the convection length of the magnetic field lines from the ion open-closed field line boundary to the satellite interception point either shortens or extends drastically, the cusp structures are the result of temporal changes in the location of the convection pattern (Trattner et al., 2005).

2. If the location of the ion open-closed field line boundary differs significantly between a new and old entry into a convection cell or flux tube, this could result in step-up or step-down ion-dispersion. Spatial structures, caused 
by these entries, will appear unchanged for satellites at all altitudes (Trattner et al., 2002a, b).

3 . If the cusp structures are caused by a variation of the reconnection rate at the reconnection location, a temporal structure will be convected with the open geomagnetic field lines and travel along the ionospheric convection direction. In agreement with the pulsating cusp model (e.g. Lockwood and Smith, 1989); a fast moving satellite will observe step-down ion-dispersion, while a slow moving satellite will observe step-up ion-dispersion.

In this paper we present observations of step-down ionenergy-dispersion. Structured cusp ion-energy-dispersion is often interpreted as temporal variations caused by periods of little or no reconnection at the magnetopause which are interspersed with periods of continuous reconnection (Tratther et al., 2002a). However, Lockwood and Smith (1992) noted that variations in the reconnection rate such as pulsed reconnection and the associated temporal poleward moving features are not the only way to introduce ion energy steps in the cusp. Solar wind parameters may vary, causing the magnetosheath ion population to change and variations in the IMF orientation may move the reconnection site and/or alter the degree of acceleration of the ions as they cross the dayside magnetopause. A change of ion acceleration may also be caused by a change of the de Hoffman-Teller velocity at the magnetopause (Trattner et al., 1999). There is also evidence that cusp ion steps can be produced in steady-state by spatial variations of the reconnection rate (e.g. Weiss et al., 1995; Onsager et al., 1995). Thus, cusp features can be interpreted as quasi-steady spatial structures during patchy reconnection. These cusp features appear as standing spatial structures and are not moving poleward. Using the pulsed reconnection model, the appearance of a standing spatial structure would be possible for a regular cycle of reconnection pulses (Trattner et al., 1999). It should also be noted that Newell and Sibeck (1993) argued that pulsed reconnection could only take place in a localized region, while Lockwood (1994) state that the travelling transient reconnection pulse scenario is not subjected to this limitation. From all this, a variety of reported stepped signatures and how they are produced and/or associated with spatial or temporal features exists:

a) Cusp structured ion-energy-dispersion (steps) produced in a quasi-steady/quasi-continuous state by spatial features: Cusp structures were explained by acceleration processes of ions in the reconnection region (Newell and Meng, 1991)

- Cusp structures were related to a discontinuity in the flow velocity across the spacecraft trajectory (Weiss et al., 1995)

- Cusp structures were interpreted in terms of quasisteady spatial structure which did not appear to be consistent with a brief localized merging event (Phillips et al., 1993)
- Cusp structures are caused by either multiple X-lines forming neighbouring flux tubes with different time histories or an evolutionary process of the field line while it is convected with the solar wind (Onsager et al., 1995; Trattner et al., 1999)

- Cusp structures results from the spacecraft crossing flow streamlines (or vortices), during patchy reconnection at the dayside magnetopause. Flow streamlines are spatial structures and each flow channel has its own history associated with the dayside reconnection (Su et al., 2001)

- Cusp structures in association with spatially separated flux tubes that most probably emanate from multiple reconnection lines (Trattner et al., 2002a, b)

- Large scale cusp structures are spatial structures related to a global ionospheric convection pattern and not the result of temporal variations in reconnection parameters (Trattner et al., 2003)

- A satellite crossing was characterized by a so-called double cusp, featuring two typical cusp ion-energydispersion events which were identified as spatial cusp structures (Trattner et al., 2005).

b) Cusp structured ion-energy-dispersion (steps) produced in a transient/intermittent state by temporal features: Cusp structures were related to the crossing of 3 successive flux transfer events (FTEs) where each individual FTE signature could be identified by the jumps in the precipitating pattern with a short recurrence rate. This is consistent with an intermittent reconnection taking place at the subsolar point on a short time scale (Escoubet et al., 1992)

- During large $B_{y}$, cusp structures in the mantle region have been shown to be coincident with thin sheets of field-aligned currents on the boundaries between the patches (Lockwood et al., 2001)

- Cusp structures have been related to the history of the reconnection rate (pulsed reconnection). A burst of reconnection is characterized by a constant energy cut-off (step) and a period with no reconnection is characterized by a jump in the cut-off (Lockwood and Smith, 1992, 1994; Lockwood et al., 2001)

- Cusp structures where found in association with the onset of plasma injection at the dayside magnetopause after southward turning of the IMF, the start of a new injection on the dayside magnetopause created a step (Escoubet et al., 2006). This was in agreement with the double cusp model developed by Wing et al. (2000) and further discussed by Sandholt et al. (2003b).

In addition to the list above, some further results achieved from ground-based data should be included to the item b). 
Temporal structures, such as flux tubes caused by reconnection pulses, are expected to move with the convection flow. Thus, poleward moving events observed by ground-based instruments is a natural consequence of a temporal feature and is not predicted by the spatial interpretation (Trattner et al., 2002a). Stepped ion-dispersion at low-altitudes have been reported in association with poleward moving patches of elevated electron temperatures between the steps, detected by incoherent scatter radars (Lockwood et al., 1993a, 1995; Lockwood and Davis, 1996), and with poleward moving cusp/cleft auroral transients, observed by optical instruments (Farrugia et al., 1998; Pinnock et al., 1995). The latter is also known as PMAFs (Poleward Moving Auroral Forms), which are ionospheric signatures of pulsed reconnection at the magnetopause (Sandholdt and Farrugia, 2007). This is in agreement with Øieroset et al. (1997) who find that PMAFs and the associated ground magnetic deflections during positive IMF $B_{y}$ are consistent with unsteady magnetopause reconnection, such as FTEs. A typical identification of a FTE is a bipolar signature in the magnetic field component normal to the magnetopause, indicating a burst of magnetic reconnection as first reported by Russel and Elphic (1978). Modern descriptions of FTEs are more refined, for instance as a signature inside the reconnected flux tube where a mixture of both magnetosheath and magnetospheric plasma exist (Farrugia et al., 1988).

In previous papers, much consideration has been given to the ion-dispersion, but relatively few papers have discussed the behaviour of cusp electron population during stepped iondispersion events, despite that there are many examples of satellite data which show structures in the electron flux. We would therefore present a more detailed study of the electron structures during these ion-dispersion events. How this structure exactly varies is not known, but there is some evidence that bursts of enhanced electron flux are caused by the satellite encountering small structures which move poleward at the convection velocity (Lockwood et al., 1993b). One possible explanation of such structures in the electron flux is the presence of field-aligned currents (Davis and Lockwood, 1996). Newell et al. (2005) have shown that electron acceleration events can and do occur in every particle source region, not only in the dayside boundary plasma sheet (BPS), which is the most common region. These acceleration events cross the boundaries surprisingly easy. However, electron acceleration events can be the manifestation of convection transients which drive field-aligned currents, and the sources of those currents on the dayside are often solar windmagnetosphere coupling. More recently, Sandholt and Farrugia (2007) have reported that the dawn-dusk precipitation is affected by PMAFs, hence showing that the asymmetry in the precipitation is not solely dependent on the well known IMF $B_{y}$ component.

The magnetosheath electrons have thermal speeds (parallel velocity) exceeding the flow speed by far throughout the magnetosheath, but because of electrostatic forces they are forced to follow the motions of ions. It was therefore expected that they enter the polar cusp only where ions are entering, rather than entering the magnetosphere along open field lines across the entire polar cap (Reiff et al., 1977). However, later on, it was found that quasi-neutrality hold throughout the cusp and not just in the region of ion injection. From this point of view, magnetosheath electrons must enter the cusp over its full latitudinal width. This requirement exists because cusp electrons with energies near $100 \mathrm{eV}$ have velocities more than an order of magnitude larger than the ions and without this requirement, they are either absorbed by the atmosphere, or mirrored and leave the magnetosphere, while convecting less than one-tenth the way through the cusp (Burch, 1985). Further, in contrast to the ions, the electrons are not expected to exhibit any energy-latitudedispersion because the electron motion is determined by the requirement of charge quasi-neutrality and not by the initial distributions of electron velocities. However, on the equatorward side of the cusp, medium-energy electrons from the high-energy tails of thermal magnetosheath plasma (1$4 \mathrm{keV}$ ) can exhibit an energy-dispersion signature similar to that of the protons. This does not yield the outer zone radiation belt electrons $(4-20 \mathrm{keV})$ or atmospheric secondary electrons (200-400 eV) (Reiff et al., 1977).

The electron precipitation is somewhat expected to be more structured than the ions, as the electrons are more mobile and therefore are responsible for most of the required field-aligned currents and for maintaining the quasineutrality of the plasma (Burch, 1985). Furthermore, many small-scale phenomena in the magnetosphere-ionosphere system may be directly driven by the solar wind (Weimer et al., 2002). This could be of relevance regarding smallscale structures inside a large scale phenomenon, especially with respect to the electron behaviour. While ion structures (dispersion) best correlate with the perturbed magnetic field and the large-scale electric field, the electron structures (burst like) correlate with the small-scale electric field variations, which are most easily explained as propagating Alfvén waves (Su et al., 2001). Chaston et al. (1999) also believe that these small-scale variations are associated with propagating Alfvén waves, whereas Matsuoka et al. (1993) suggests that the Alfvén waves are generated in association with the particle injection into the magnetosphere when reconnection occurs. From this, the Alfvén waves play an important role in the energization of electrons. Such waves propagating in the dayside auroral oval and in the vicinity of the cusp have been observed and identified by FAST satellites in narrow regions transverse to the field, typically of the order of $3 \mathrm{~km}$ and with highly non-sinusoidal irregular wave forms (Chaston et al., 1999). 


\section{Instrumentation}

REIMEI (synonymous with dawn) is a small low-altitude satellite which follows a sun-synchronous orbit in the meridian of 12:50-00:50 local time at $640 \mathrm{~km}$ altitude. The satellite is equipped with 3 high resolution instruments: i) Multispectral Auroral imaging Camera (MAC), ii) Low-energy auroral particle instrument with an Electron and Ion energy Spectrum Analyzer (EISA) and iii) Plasma CuRrent Monitor (CRM). In this study, a high resolution mode has been chosen for the particle instrument giving a temporary resolution of $480 \mathrm{~ms}$ and a spatial resolution of $600 \mathrm{~m}$. As a part of the CMR, a swept Langmuir Probe (LP) with 640 $\mathrm{ms}$ between each sweep is onboard the satellite, where the electron density and temperature can be estimated from the current-voltage-characteristics. Further description of the instruments can be found at: http://www.darts.isas.jaxa.jp/stp/ reimei/instruments.html.

The EISCAT Svalbard Radar (ESR) in Longyearbyen, located at $75.27^{\circ} \mathrm{N}$ and $11.65^{\circ} \mathrm{E} \mathrm{CGM}$, is a monostatic incoherent scatter radar $(500 \mathrm{MHz})$ with two parabolic antennas; a steerable $32 \mathrm{~m}$ in diameter and a fixed $42 \mathrm{~m}$. The latter points at $182.1^{\circ}$ in azimuth and $81.6^{\circ}$ in elevation, aligned with the geomagnetic field at a height of $300 \mathrm{~km}$. For this campaign, the $32 \mathrm{~m}$ antenna was pointed to the closest point of the satellite footprint trajectory for about 10 to $15 \mathrm{~min}$ before and after each pass, and otherwise field-aligned. At a height of $300 \mathrm{~km}$, the transversal resolution is about $7 \mathrm{~km}$ and $5 \mathrm{~km}$ for the $32 \mathrm{~m}$ and $42 \mathrm{~m}$ dishes, respectively. The radar was operated in a 16 bit alternating code and the experiment was a combination of Hilde and Steffe ESR modulation schemes, the latter whenever both antennas pointed field-aligned. Steffe has a radar code for moderate range resolutions from $3 \mathrm{~km}$ covering all ionospheric heights up to $900 \mathrm{~km}$, optimised for measurements at high antenna elevations. Hilde has a dual antenna code switching between the antennas on a pulse-to-pulse basis $(10 \mathrm{~ms})$ with similar resolutions as Steffe, but in contrast to Steffe where both antennas point field aligned, Hilde allows the $32 \mathrm{~m}$ antenna to have a different elevation. More information about the ESR experiments can be found at: https://www.eiscat.se/ about/experiments2/experiments and detailed description of the ESR facility and techniques can be found in Wannberg et al. (1997).

It is crucial in these observations to keep the resolution in time has high as possible, i.e. 6.4 s. The range resolution was not optimal due to low signal-noise ratios which left too few useful gates. Consequently, integration in altitude was required. Several combinations of height-integration and altitude ranges were tested. The one giving the most satisfactory result proved to be a height-integration in the altitude range from $200 \mathrm{~km}$ and $300 \mathrm{~km}$ with a default setting between each step-size.

As ground-based supporting instruments, the Cutlass radars $(8-20 \mathrm{MHz})$ located in Finland $\left(59.78^{\circ} \mathrm{N}\right.$ and

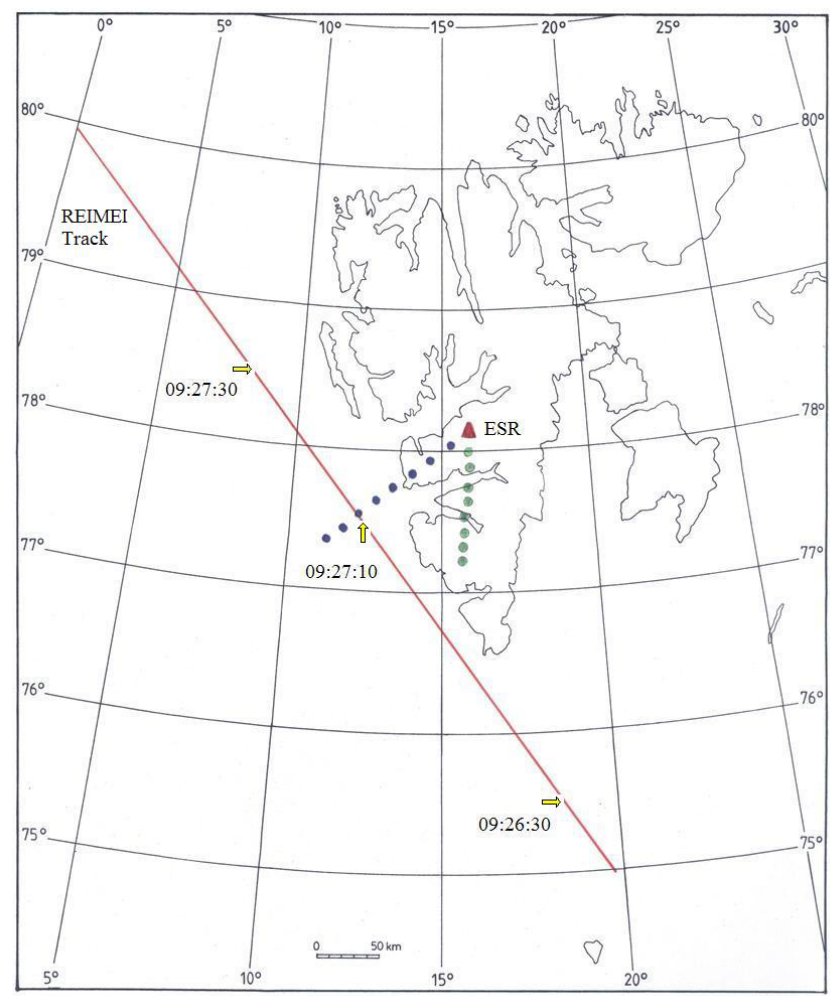

Fig. 1. Map showing the REIMEI trajectory projection and the ESR beams. The times marked on the satellite trajectory are in UT. The beams for the 42 - and $32 \mathrm{~m}$ antenna are marked by green and blue circles, respectively. The circles are at $100 \mathrm{~km}$ intervals in height.

$\left.105.53^{\circ} \mathrm{E} \mathrm{CGM}\right)$ and Iceland $\left(64.59^{\circ} \mathrm{N}\right.$ and $\left.69.65^{\circ} \mathrm{E} \mathrm{CGM}\right)$, the Finnish pulsation magnetometer in Barentsburg $(\sim 40 \mathrm{~km}$ south-west from Longyearbyen) and the magnetometer network IMAGE (International Monitor for Auroral Geomagnetic Effect) were used. The Cutlass radar is a part of the Super Dual Auroral Radar Network (SuperDARN) while IMAGE, consisting of several (30) fluxgate-magnetometers located in northern Europe and Russia, covers the geographic latitudes from $58^{\circ}$ to $79^{\circ}$.

\section{Observations}

On 1 February 2006, the REIMEI satellite flew past the ESR facility at $\sim 610 \mathrm{~km}$ height with the shortest range of $628 \mathrm{~km}$ at 09:27 UT. During this time, the ESR $32 \mathrm{~m}$ antenna was pointed at $233.8^{\circ}$ in azimuth and $78.7^{\circ}$ in elevation. This direction gives an angle between the antenna beams of $8.9^{\circ}$, which is equivalent to a horizontal distance of $\sim 47.5 \mathrm{~km}$ at $300 \mathrm{~km}$ height. The satellite trajectory and the radar field of view are shown in Fig. 1. The filled circles mark radar volumes at intervals of $100 \mathrm{~km}$ in altitude.

The magnetospheric configuration depends not only on the solar wind at any particular moment, but also upon its 


\section{February 2006 REIMEI EISA}

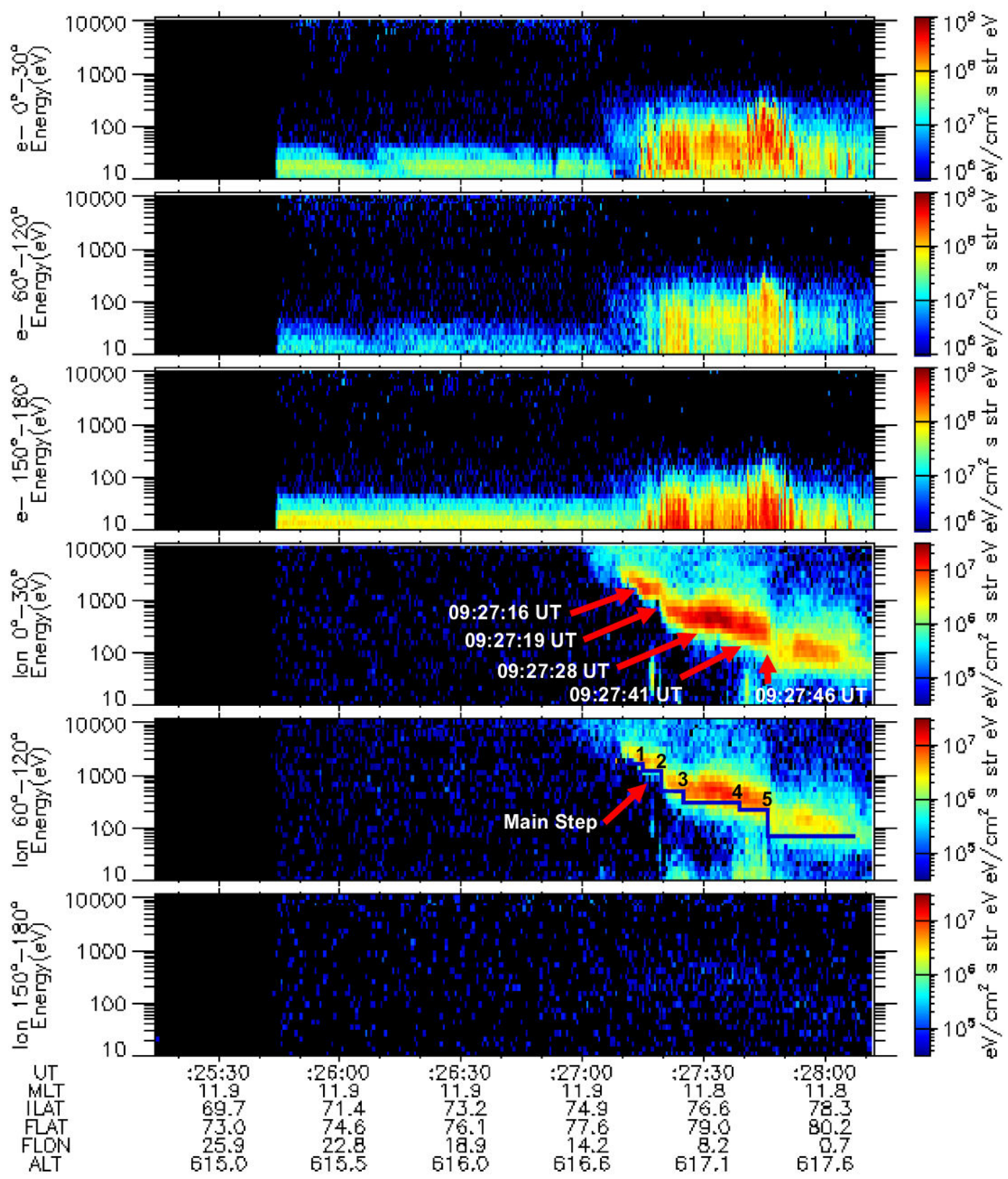

UT from FEB $1,2006 \quad 9: 25: 14$ UT

Fig. 2. In this REIMEI EISA plot, the 3 upper panels show the electron flux and energy versus time. The first from top is for pitch angles $0^{\circ}-30^{\circ}$ (down), the second for $60^{\circ}-120^{\circ}$ and the last for $150^{\circ}-180^{\circ}$ (up). The 3 lower panels display ion flux and energy correspondingly. The stepped ion-energy-dispersion is marked with red arrows and their respective start time. The largest transition is the 2 nd step, which are marked as the main step.

parameters in the preceding hours. This is particularly important for the inner magnetosphere. The interplanetary magnetic field (IMF) profiles, which were obtained by the ACE satellite (not shown) at the Lagrange point (L1), had been relatively steady for at least $2 \mathrm{~h}$ prior to the time of interest: $B_{z}<0(-3 \mathrm{nT}), B_{y}>0(+3 \mathrm{nT}), B_{x}<0(-5 \mathrm{nT})$ and
$<B>\sim 6 \mathrm{nT}$. The turn of $B_{z}$ from northward to southward occurred at 07:12 UT (L1), immediately before this steady period. The solar wind speed was around $330 \mathrm{~km} / \mathrm{s}$. Since the solar wind data are recorded at L1, there is a delay of $1 \mathrm{~h}$ and $15 \mathrm{~min}$ before the effects are seen in the magnetosphere. 


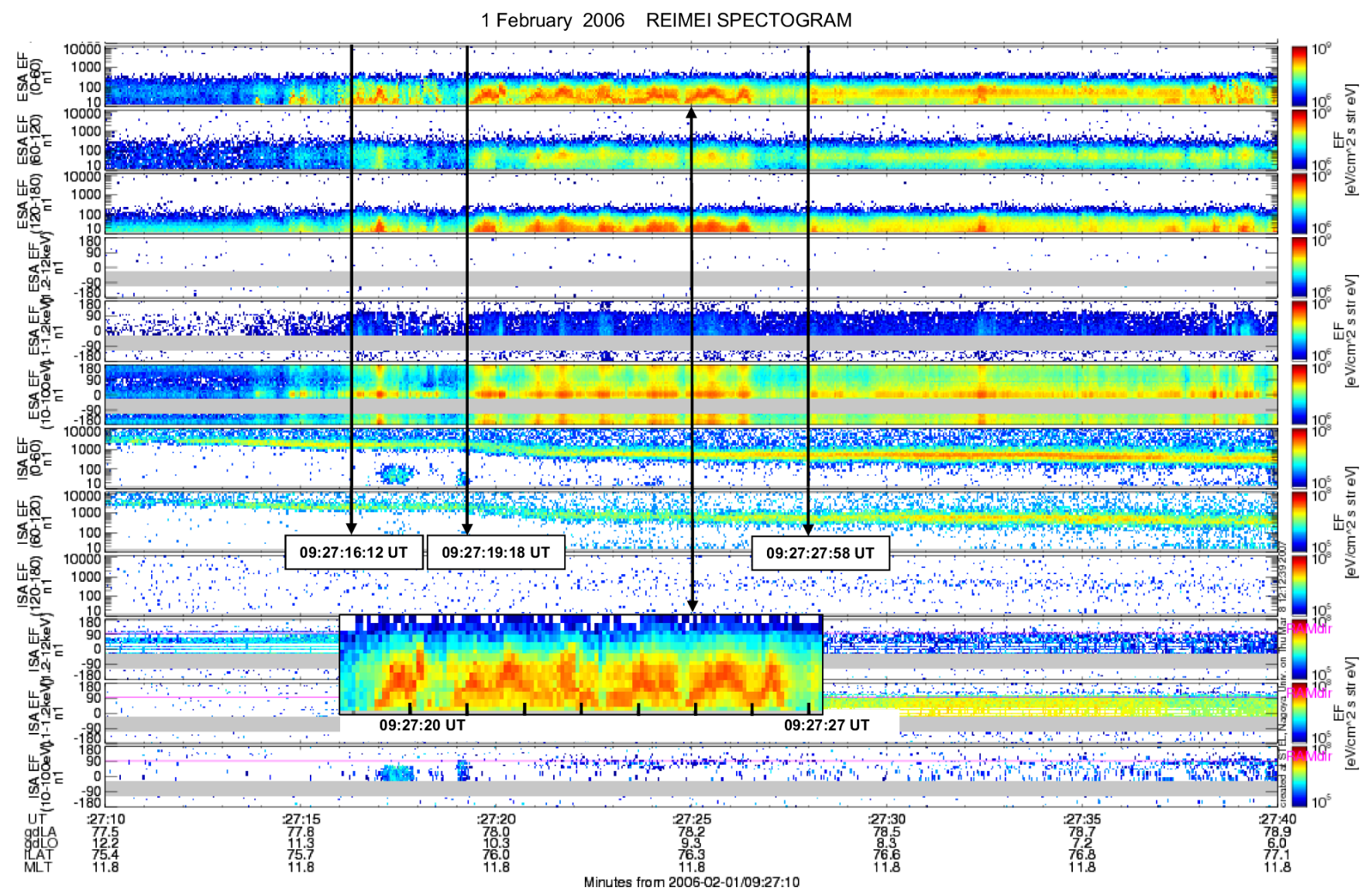

Fig. 3. High resolution electron- (panels 1-6) and ion- (panels 7-12) spectrogram: panels 1-3 and 7-9 (starting from the top) is flux and energy versus time and pitch angles $\left(0^{\circ}-60^{\circ}\right.$ (down), $60^{\circ}-120^{\circ}$ and $120^{\circ}-180^{\circ}$ ), panels $4-6$ and $10-12$ is the flux and pitch angles versus time and energy channel $(10-100 \mathrm{eV}, 0.1-1.2 \mathrm{keV}, 1.2-12 \mathrm{keV})$. The 3 vertical black lines represent the start of the first 3 steps in the ionenergy-dispersion, as well as the start of rapid fluctuations in the electron data (the 4th and 5th step, $\sim 09: 27: 41$ UT and $\sim 09: 27: 46$ UT, are not shown). The periods of no or almost no electron are clearly seen. The frame seen at the bottom of the figure shows an enlargement of the interval between $\sim 09: 27: 19$ UT and $\sim 09: 27: 27$ UT. The electron fluctuations start at $\sim 09: 27: 19: 18$ and end at $\sim 09: 27: 26: 30$ UT.

In the satellite data, Figs. 2 and 3, continuously decreasing ion energy was clearly seen, followed by a step-like decrease. The downward ion-precipitation was in the range from $3 \mathrm{keV}$ and down to $50 \mathrm{eV}$. Additionally, during the iondispersion the REIMEI data show quasi-periodic fluctuations in the electron energy and flux. REIMEI started recording ion activity at $\sim 09: 27: 10 \mathrm{UT}$ and ended at $\sim 09: 28: 06 \mathrm{UT}$. The first ion-step started at $\sim 09: 27: 16 \mathrm{UT}$, a small and short step. The second and main step started at $\sim 09: 27: 19$ UT, the third at $\sim 09: 27: 28 \mathrm{UT}$, the fourth at $\sim 09: 27: 41 \mathrm{UT}$ and the final step was observed at $\sim 09: 27: 46$ UT. The energy range during the ion precipitation was: a) 3$1.5 \mathrm{keV}$ before the first step (09:27:10-09:27:16 UT), b) $1.5-1 \mathrm{keV}$ after step 1 (09:27:16-09:27:19 UT), c) $1 \mathrm{keV}-$ $300 \mathrm{eV}$ after step 2 (09:27:19-09:27:28 UT), d) 300-150 eV after step 3 (09:27:28-09:27:41 UT), e) $150-100 \mathrm{eV}$ after step 4 (09:27:41-09:27:46 UT) and f) 100-50 eV after step 5 (09:27:46-09:28:06 UT). Since the fourth and final step is far away from the ESR facility, only the first 3 steps are con- sidered in Fig. 3, while all ion-steps are indicated in Fig. 2. By using the model of predicted ion precipitation at lowaltitudes due to the observed ion energy in the ionosphere (Lockwood and Smith, 1994), we have estimated the corresponding time of reconnection for each ion step observed, assuming an Alfvén velocity of $100 \mathrm{~km} / \mathrm{s}$ : a) corresponds to $\sim$ 09:23 UT, b) corresponds to $\sim 09: 22 \mathrm{UT}, \mathrm{c}$ ) corresponds to $\sim 09: 17 \mathrm{UT}, \mathrm{d}$ ) corresponds to $\sim 09: 15 \mathrm{UT}, \mathrm{e}$ ) corresponds to $\sim 09: 13 \mathrm{UT}$, and f) corresponds to $\sim 09: 10 \mathrm{UT}$. This gives an average recurrence time of $2.4 \mathrm{~min}$ (and individual recurrence time of $47 \mathrm{~s}, 328 \mathrm{~s}, 100 \mathrm{~s}, 145 \mathrm{~s}$ and $105 \mathrm{~s}$, respectively). Looking at the electron data, we see they fluctuate most of the time, but there are also times with small gaps in the data. In this context and later on, gaps in the data do not mean lack of data, but rather small intervals with no or almost no electrons. It should be noted that before each step-down in the ion-data, there are such gaps. Furthermore, the ion-step corresponds with the start of electron fluctuations, on the rising flank from a gap. Between each electron gap, the energy 


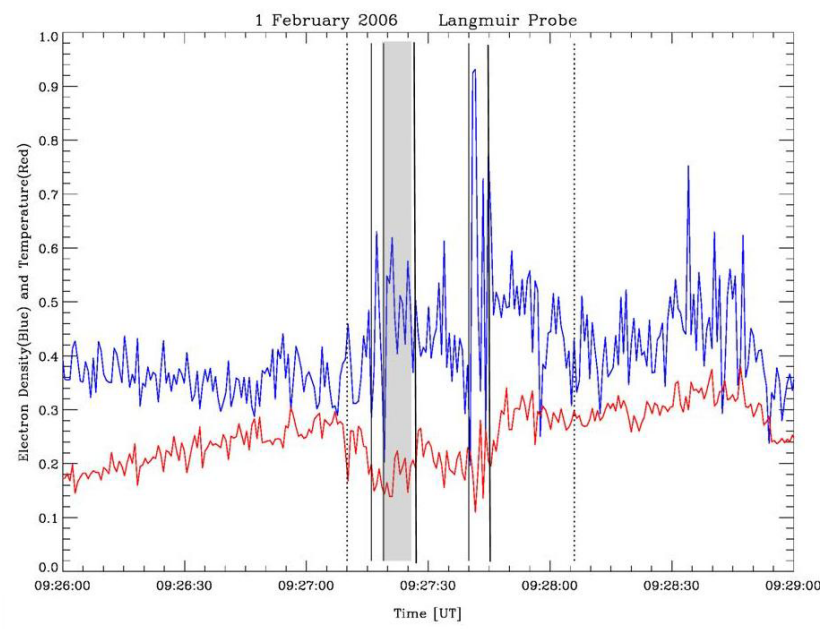

Figure 4 shows the Langmuir Probe (LP) data. This data are not properly calibrated so the absolute values of density and temperature (top panel, blue and red lines, respectively) are not reliable, but the relative variations are expected to be real (at least on short time-scale). Since the ESR data are quite noisy at the altitude of the satellite trajectory, it is not straightforward to calibrate the LP. Nevertheless, the figure shows clearly that both the electron density and temperature are influenced by crossing the cusp. The ion-dispersion as well as the electron fluctuations are somewhat reflected in the LP data. The first dotted line ( 09:27:10 UT) indicates when ions are observed and the last dotted line ( 09:28:06 UT) corresponds to the end of the observed ions. The first solid lines correspond to the 1st ion-step and end of electron gap ( $\sim 99: 27: 16$ UT), the next solid line indicate the 2 nd and main ion-step ( $\sim 09: 27: 19 \mathrm{UT})$, the shaded area shows the start $(\sim 09: 27: 19: 18 \mathrm{UT})$ and end time $(\sim 09: 27: 26: 30 \mathrm{UT})$ of the electron fluctuations during the main step. The third solid line, slightly offset from the shaded area, mark the start time of the 3rd ion-step ( 09:27:28 UT) and the fourth solid line is the 4th ion-step ( 09:27:41 UT), which corresponds to the start of the electron fluctuations again. The fifth solid line indicates the start of the 5th and final ion-step ( 09:27:46 UT). The lower panel in Fig. 4 illustrates how the rising flank (blue triangle), after a time lag with considerable gaps in the electron density, is in accordance with the start of each step in the ion-dispersion. The red circles correspond to the border between each gap/step, hence the corresponding time is very close to the times of observed ion steps in the data.

During the time of interest, 09:27 UT \pm 1 min, marked as a

Fig. 4. The upper panel shows the Langmuir Probe electron-density (blue) and temperature (red) versus time. The first dotted vertical line (09:27:10 UT) indicates when the ion is observed and the last dotted line (09:28:06 UT) corresponds to end of the observed ions. The first solid lines correspond to the border of the first ion step and electron gap, and so on: $\sim 09: 27: 16 \mathrm{UT}, \sim 09: 27: 19 \mathrm{UT}$, $\sim 09: 27: 28$ UT, $\sim 09: 27: 41$ UT and $\sim 09: 27: 46$ UT. The shaded area corresponds to the time interval between $\sim 09: 27: 19: 20$ UT and $\sim 09: 27: 26: 30$ UT, the main period of electron fluctuations. The lower panel illustrates how the rising flanks (blue triangle) after considerable gaps in the electron density are in accordance with the start of each step in the ion-dispersion. The red circles correspond to the border between each gap/step as above: $\sim 09: 27: 16 \mathrm{UT}$, $\sim 09: 27: 19$ UT, $\sim 09: 27: 28$ UT, $\sim 09: 27: 41$ UT and $\sim 09: 27: 46$ UT.

and flux vary with frequencies between $0.5-0.8 \mathrm{~Hz}$. Most of the electron fluctuations are visible after the main ionstep (that is, between the $2 \mathrm{nd}$ and $3 \mathrm{rd}$ steps), but the rapid fluctuations are also evident between the 4th and 5th step (not shown). In addition, high fluxes in the ion data correspond with low fluxes in the electron data and vice versa. For the ions, this is most clearly seen in Fig. 3 from about $\sim 09: 27: 31$ UT to $\sim 09: 27: 37$ UT. At this particular ion-step, starting at 09:27:28 UT, the fluctuations in the electrons are almost absent and the increased ion fluxes are in the energy range from $150-300 \mathrm{eV}$. black/yellow dotted line in Fig. 5, the ESR data show some activity in the electron precipitation at F-region, weak but still visible for the $32 \mathrm{~m}$ antenna data $\left(\sim 7 \mathrm{E} 10 \mathrm{~m}^{-3}\right)$, and clearer for the $42 \mathrm{~m}$ antenna data $\left(\sim 1.4 \mathrm{E} 11 \mathrm{~m}^{-3}\right)$. The red square seen in the $32 \mathrm{~m}$ density data (top left Fig. 5) is caused by the REIMEI satellite, crossing the antenna beam. It should be noted that while the $42 \mathrm{~m}$ antenna beam is looking "along" a field line, the $32 \mathrm{~m}$ antenna beam is crossing parts of other field lines. It is interesting to notice that while an increased electron density is seen in the field-aligned data $(42 \mathrm{~m})$, the electron temperature $\left(<1500^{\circ} \mathrm{K}\right)$ is not particularly high. This indicates that the enhanced density is related to drifting patches and not particle precipitation. In contrast, the electron temperatures observed in the oblique data $(32 \mathrm{~m})$ were within levels of ordinary background plasma, about $2000^{\circ} \mathrm{K}$. The measured ion temperature was about the same in both datasets, $\sim 800^{\circ} \mathrm{K}$, close to the modelled neutral temperature. The different temperatures are difficult to see in Fig. 5 due to $120 \mathrm{~s}$ integration time, since this figure indicates an electron temperature of about $1500^{\circ} \mathrm{K}$ for both datasets. However, a detailed study shows the quoted temperatures above (figure not shown). In the raw density spectra (Fig. 6), a fluctuation could be seen in both $32 \mathrm{~m}$ and $42 \mathrm{~m}$ antenna data, but interestingly, they are anti-correlated. The raw electron density in this figure is height integrated 

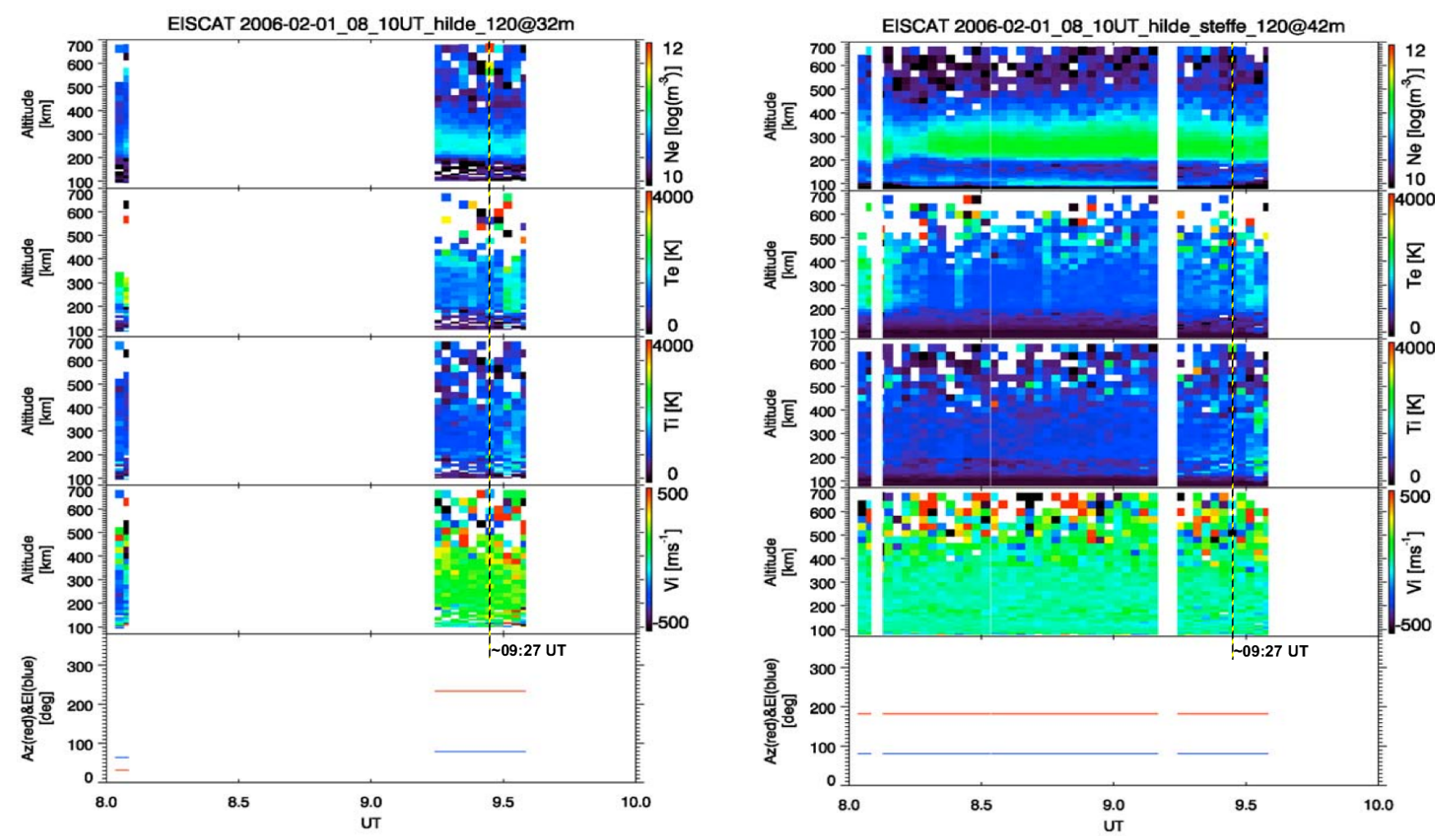

Fig. 5. Standard analysis of the ESR data from the $32 \mathrm{~m}$ antenna (left) and the $42 \mathrm{~m}$ antenna (right) where the panels show from the top to the bottom: the electron density, the electron temperature, the ion temperature and the ion drift velocity. The integration time is $120 \mathrm{~s}$ and the black/yellow line corresponds to the time that REIMEI passes the $32 \mathrm{~m}$ antenna beam.

from $200-300 \mathrm{~km}$. The rapid fluctuations in the ESR data are interpreted as real, since the error-bars are small relative to the fluctuations themselves. Comparing the electron density from the $32 \mathrm{~m}$ ESR data with the satellite data, we note a resemblance in the variations with time. Equivalent with the observed LP data, a minimum point at 09:27:08 UT in the electron density is seen in the $32 \mathrm{~m}$ radar data just before the ions are observed by EISA. The following maximum at $\sim 09: 27: 13$ UT, also seen in the LP data, is close to the start of the observed ions. Thereafter, a minimum at $\sim 09: 27: 19$ UT is seen (shaded area), which corresponds to the LP data and seems to be associated with the 2 nd and main ion-step. Afterwards, the electron density increases again, reaching the next maximum at $~ 09: 27: 28$ UT. Just as for the LP data, this is analogous to the 3rd ion-step. Taken into account that the satellite spends a very short time in the radar volume, only a small part of the data in time would be expected to match.

In Fig. 7 the satellite trajectory has been plotted in the plasma convection pattern obtained from SuperDARN. The characteristic two-cell patterns of ionospheric convection are seen, since the IMF is southward. The two convection maps, 09:20:00-09:22:00 UT and 09:30:00-09:32:00 UT, indicate that the satellite has just entered the convection cell (crossed the flux tube) when ion-dispersion is seen in the data. The convection speed observed by the SuperDARN radar was about $750 \mathrm{~m} / \mathrm{s}$ in the east-west direction (dusk-dawn). By influence of the magnetic curvature force and during $B_{y}>0$, patches of newly opened flux will move westward/eastward in the Northern/Southern Hemisphere, respectively. For $B_{y}<0$, the flow directions are reversed (Lockwood et al., 2001). The electric potential was about $60 \mathrm{kV}$, indicating a cross polar cap potential drop high enough to influence the ionosphere down to $500 \mathrm{~km}$ (Lockwood and Smith, 1992), which is well below the satellite altitude.

As shown in Fig. 8, the pulsation-magnetometer did record some micro-pulsations, Pc-1 (0.2-5 Hz) and Pc-3 (22$100 \mathrm{mHz}$ ). The Pc-1 is dominating some hours before our time of interest while Pc-3 is going on for several hours and also recorded as low as $L=3$. The $\mathrm{L}$-value for Barentsburg is 15.65 at sea level $\left(75.36^{\circ} \mathrm{N} 109.87^{\circ} \mathrm{E}\right.$ CGM $)$. Also, faint disturbances, $\pm 30 \mathrm{~min}$ from 09:00 UT are seen around $0.6 \mathrm{~Hz}$. Figure 9 shows a raw spectrum plot in both the north-south and east-west inductor. The data has been sampled in $40 \mathrm{~Hz}$ and for instance, 512 points FFT with 32 points overlapping means $12.8 \mathrm{~s}$ window which makes 15 spectra for $3 \mathrm{~min}$. The plot does not show a clear association with the rapid electron fluctuation during the time of interest. 

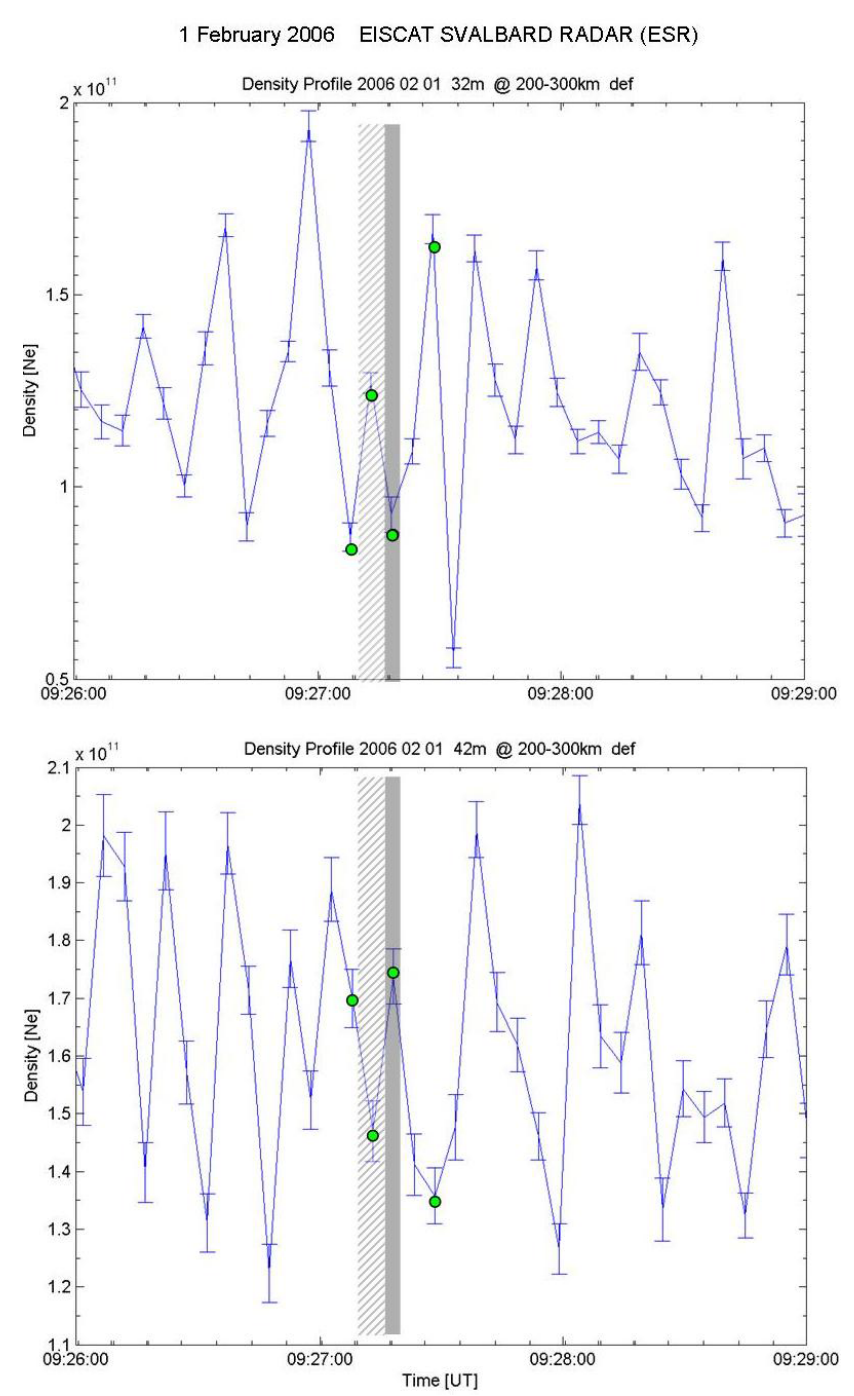

Fig. 6. Plot of the raw electron density versus time measured with the $32 \mathrm{~m}$ antenna (upper figure) and the $42 \mathrm{~m}$ antenna (lower figure). The integration in height is $100 \mathrm{~km}$. Note the anti-correlation between the $32 \mathrm{~m}$ and $42 \mathrm{~m}$ during the time of interest, marked with green circles at $\sim 09: 27: 08 \mathrm{UT}, \sim 09: 27: 13 \mathrm{UT}, \sim 09: 27: 19 \mathrm{UT}$ and $\sim 09: 27: 28$ UT. The diagonally shaded area corresponds to data dumps taken when the REIMEI passes over the $32 \mathrm{~m}$ antenna beam, while the shaded area indicates the start of the main ion step in the energy dispersion.

By looking at the magnetograms from the IMAGE network $\left(71^{\circ}-76^{\circ} \mathrm{MLAT}\right)$, with $20 \mathrm{~s}$ resolution data, some interesting features were found. A sequence of poleward moving impulse events is observed in the interval 08:25-09:25 UT. The average recurrence time of major events is approximately $7 \mathrm{~min}$. At the same time as the ion-dispersion, a poleward moving positive bay in the X-component was observed at all stations north of Sørøya located at $67.46^{\circ} \mathrm{N}$ CGM, marked as red triangles in Fig. 10 (Sørøya is not included in the figure). Simultaneously, a positive bay in both the
Y- and Z-components occurs at all stations at the same time (not shown). The southward turning of the IMF corresponds very well with the negative deflection in the X-component starting at Bjørnøya 08:27 UT (green triangles). Finally, the previous estimated starting time of each reconnection obtained from the REIMEI data matches the variations in the Xcomponent for Bjørnøya (blue triangles). Starting from the left, the first blue triangle at $\sim 09: 10$ UT corresponds to an injection of ions due to a reconnection and the associated final ion-step (f), thereafter: 09:13 UT, 09:15 UT, 09:17 UT, $\sim 09: 22$ UT and $\sim 09: 23$ UT correspond to the forth step (e), third step (d), second step (c), first step (b) and the start of ion precipitation (a), respectively. The poleward moving velocities during the ion dispersion are between $3-4 \mathrm{~km} / \mathrm{s}$, which is very fast, while the poleward moving velocity just after the IMF turning is about $1.75 \mathrm{~km} / \mathrm{s}$, which is on the order of the normal convection speed in the ionosphere.

\section{Technical limitations}

Before we discuss the ion-dispersion and electron structures, we would like to highlight some limitations and expected difficulties due to the spatial/temporal ambiguity.

As the convection velocity is quite high, the limited time resolution of the radar excludes observations of simultaneous fluctuations in data from the two antennas. The drift time through the antenna beam need to be more than two times the integration time. In order to satisfy this, the convection speed should not exceed $525 \mathrm{~m} / \mathrm{s}$. A formation/structure moving with a speed of $750 \mathrm{~m} / \mathrm{s}$ will use $\sim 10 \mathrm{~s}$ to pass the $32 \mathrm{~m}$ antenna beam at a height of $300 \mathrm{~km}$, hence, if there is any fluctuation inside this formation, it is not sure that the radar will be able to register that. It takes even less time to pass by the $42 \mathrm{~m}$. Also, at lower altitudes than $300 \mathrm{~km}$, less and less convection speed is required. Accordingly, if no fluctuations are seen in the radar data, it cannot be used as an argument that there are no fluctuations at all. On the other hand, if fluctuations are seen in the data despite the poor time integration, this could be used as a positive support.

Furthermore, a formation/structure will take about 1 min to drift from one antenna to the other. If any pronounced signature is seen in one of the antennas, it should also appear for the other antenna, slightly displaced, as long as we are talking about a steady drifting spatial structure. However, a small and rapid temporal change with size less than $4.8 \mathrm{~km}$ inside this structure will be difficult to see, regardless of the height, due to the integration time. If a large scale structure covers both antennas, it should be possible to see distinct signatures at the very same time in both antennas, provided that the time change is larger than the integration time.

Due to the distance between the antennas, it will be difficult to see fluctuations of spatial nature in the electron precipitation if the scale-size at $300 \mathrm{~km}$ height is less than $\sim 47 \mathrm{~km}$. If the scale size is larger, it should be possible to see similar 


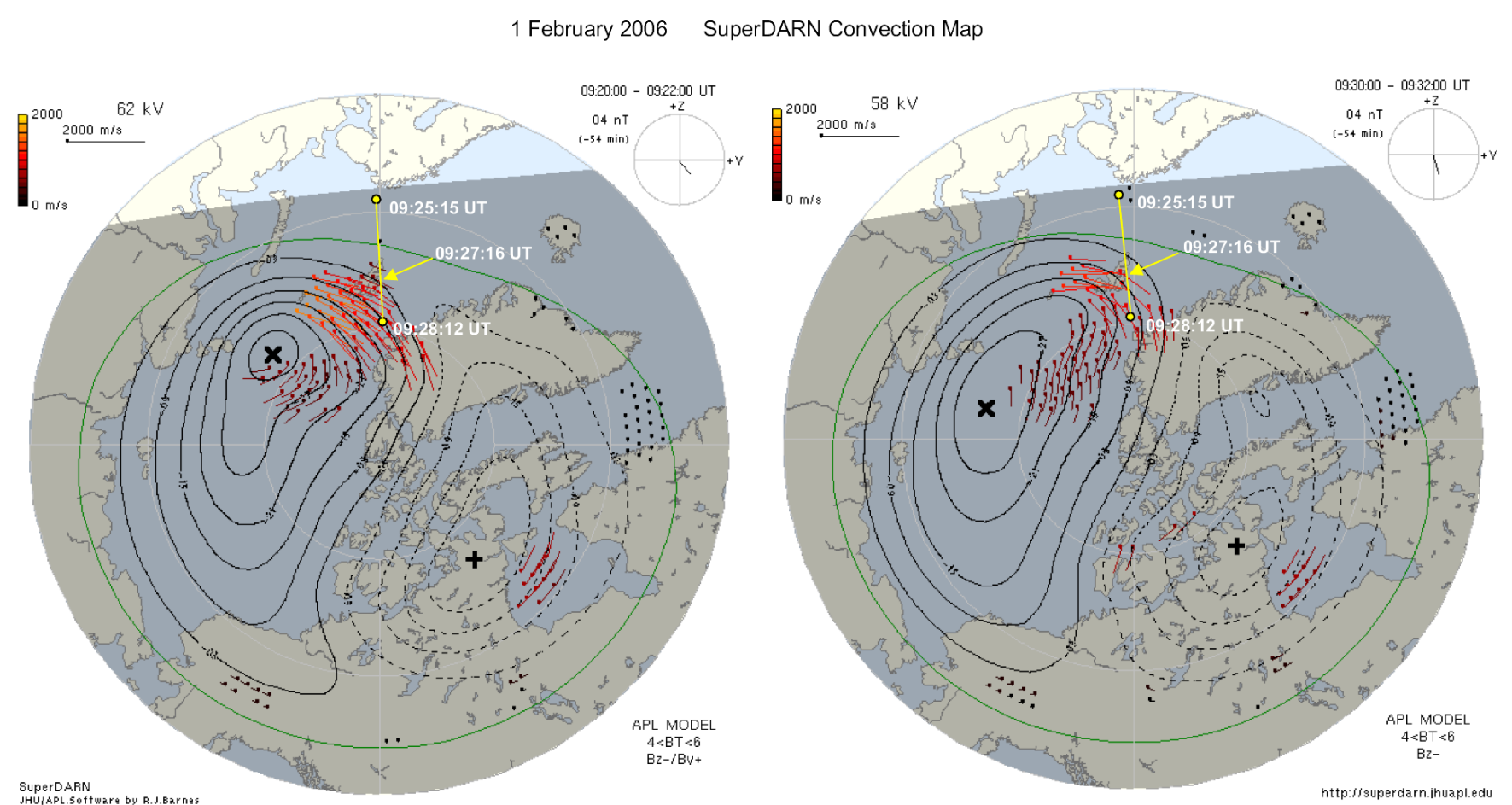

Fig. 7. SuperDARN plasma convection data are shown for 09:20:00-09:22:00 UT (left) and 09:30:32 UT (right). The satellite trajectory is indicated on both maps. The closest pass to the ESR $32 \mathrm{~m}$ antenna is about 09:27:16 UT.

fluctuations in both the oblique data (32 $\mathrm{m})$ and field-aligned data $(42 \mathrm{~m})$, slightly displaced. Also, if the electron fluctuations are temporal, the same fluctuations should be expected to be seen in both $32 \mathrm{~m}$ and $42 \mathrm{~m}$ at the very same time for large-scale structures.

Additionally, it should be kept in mind that observations from a single satellite only, makes it difficult to reveal whether steps in the cusp ion distribution signatures are moving or not, hence, hence conclusion of temporal or spatial variations from this will not be precise. A better diagnostic could be obtained by using more satellites and/or satellite(s) in combination with ground-based instrument(s). The same applies for the electron behaviour as well. In general, satellites at different altitudes will encounter different signatures of the dispersion (step up/step down), since a highaltitude (slow moving) satellite will stay longer in the cusp than a low-altitude (fast moving) satellite, the latter will observe less structures. However, if cusp structures are spatial, both satellites should encounter the same number of structures as long as the whole cusp does not move. If it moves, the high-altitude satellite might cross a single structure several times while the low-altitude satellite would encounter it only once. By using satellites that cross the cusp at the same altitude and about the same time, they might encounter quasiperiodic pulsations which could be mistaken for spatial structures, but if the satellites cross the cusp at the same altitude at different times, this could give more reliable information about the cusp structures. If the cusp structures are caused by reconnection pulses, the satellites will encounter them at different latitudes and the cusp structure will be temporal. If the cusp structures are caused by for example multiple Xlines, the satellites will encounter them at the same latitude and the cusp structure would be a spatial feature (Trattner et al., 2002a). In our case, only one single satellite is used, hence the above improvements by using more satellites do not apply to our data. However, we do combine satellite and ground-based measurements. The latter is able to distinguish between temporal and spatial structures, but they suffer from lower time- and space resolution than satellite measurements. Also, an incoherent scatter radar cannot unambiguously define the transient signatures in the cusp as being caused by precipitating ions (e.g. Lockwood et al., 1993a).

\section{Discussion}

Slow changes in the energy of cusp precipitation have previously been explained by the time-of-flight effect when open magnetic flux emerges from an X-line at the dayside magnetopause allowing magnetosheath plasma to "fly" towards the ionosphere while the newly opened field lines simultaneously convect. As a satellite at low-altitude crosses field lines that have been open for increasingly longer times and convecting further away from the open-closed boundary, 


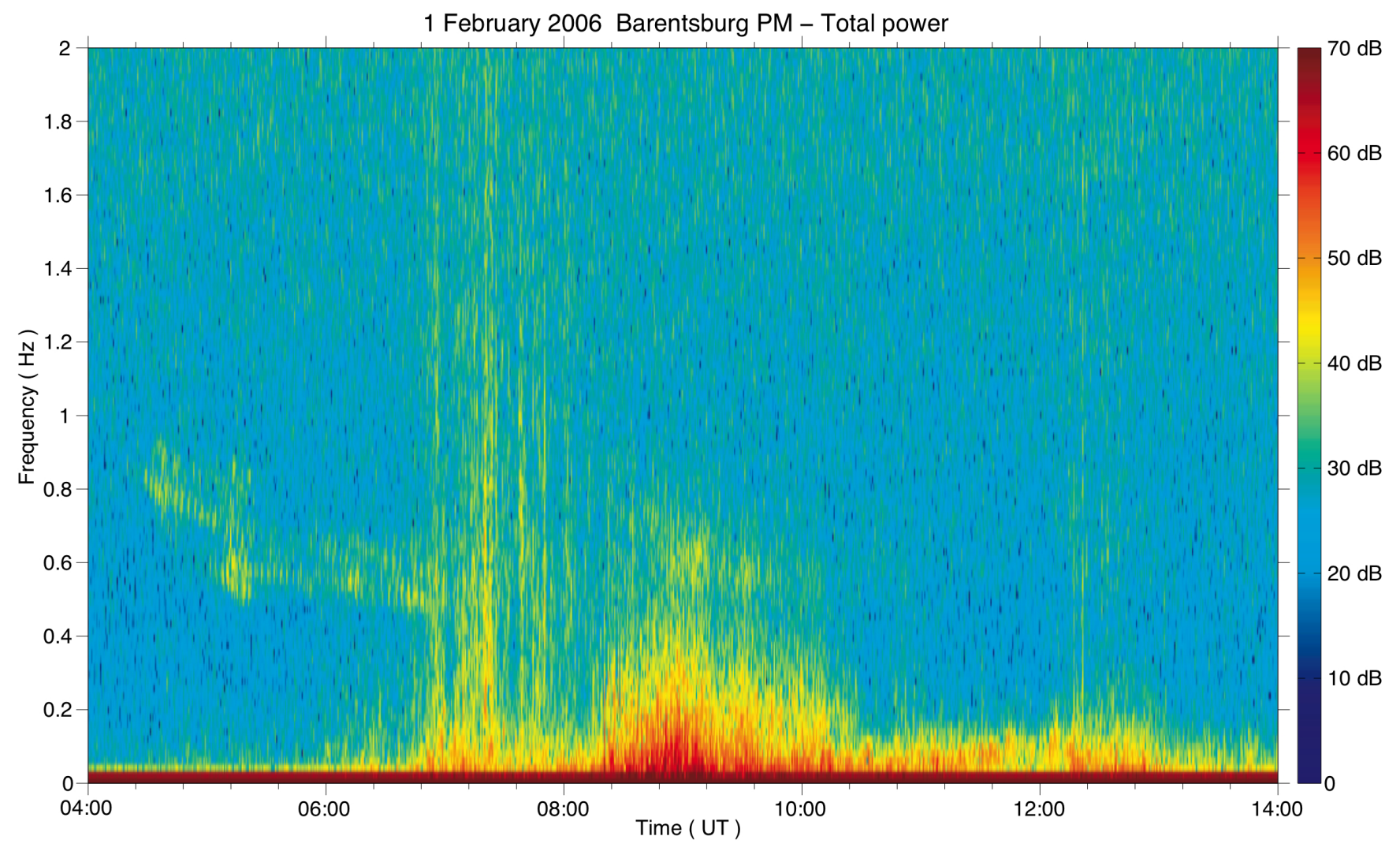

Fig. 8. Sonogram produced from the Barentsburg pulsation magnetometer. Pc-1 (0.2-0.5 Hz) and Pc-3 (22-100 mHz) are observed. Around our time of interest (09:27 UT), a faint activity is seen around $0.6 \mathrm{~Hz}$.

progressively slower ions reach its ion instrument. For southward IMF the convection is generally poleward, and a poleward orbiting satellite such as REIMEI in this event sees ions with decreasing energy. Rapid changes in the energy of precipitating ions have been explained by sudden temporal changes of the reconnection rate controlling the convection (e.g. Lockwood and Davis, 1995). Alternatively, Trattner et al. (2003) showed that some events could rather be explained by a more complicated magnetic field topology involving multiple open-closed boundaries. This spatial structure might then exist relatively stationary. We will discuss the cause of stepped ion-dispersion as well as the observed electron fluctuations.

Both the polarity and the size of IMF $B_{y}$ have impact on the magnetosphere. One of the most interesting effects is the regulation of the cusp position, both in latitude (ILAT) and longitude (MLT), which is considered to be a unique signature of magnetic reconnection through the magnetopause. According to Zhou et al. (2000), the centre of the reconnection site moves duskward in the Northern Hemisphere for positive $B_{y}$. Also Field Aligned Currents (FACs) seem to be controlled by the IMF parameters, a phenomenon which has been observed between ion-dispersion steps during large positive $B_{y}$ (Lockwood et al., 2001). It should be noted that while Lockwood et al. (2001) predict that FACs exist around cusp ion steps produced by pulsed reconnection, Ohtani et al. (1996) concluded from Viking and DMSP measurements that FAC systems appeared to be quasi-stationary. The cusp ion energy is also influenced by the location of the X-line and the degree of acceleration of the ions as they cross the dayside magnetopause (Lockwood and Smith, 1990, 1992, 1994). In our case, the $B_{y}$ was also positive but not particularly high $(\sim 3 \mathrm{nT})$, but it is high enough for excitation of dawn-dusk asymmetries in plasma convection (see Fig. 7) and relatively intense FACs in the distorted dusk cell are not excluded.

Also, since the IMF conditions have been steady for a long time, it is not likely that the ion-dispersion have been influenced by changes in the X-line location (Trattner et al., 2002a). However, this does not exclude that multiple $X$-lines can be involved. In fact, as previously mentioned in the introduction, Trattner et al. (1999) suggested that spatial cusp structures could be caused by either multiple X-lines forming neighbouring flux tubes with different time histories or by an evolutionary process of the field line while it is convected with the solar wind. Crossing the boundary into such a spatially separated flux tube (or convection cell) would appear as a step in the ion-energy-dispersion, due to the different 

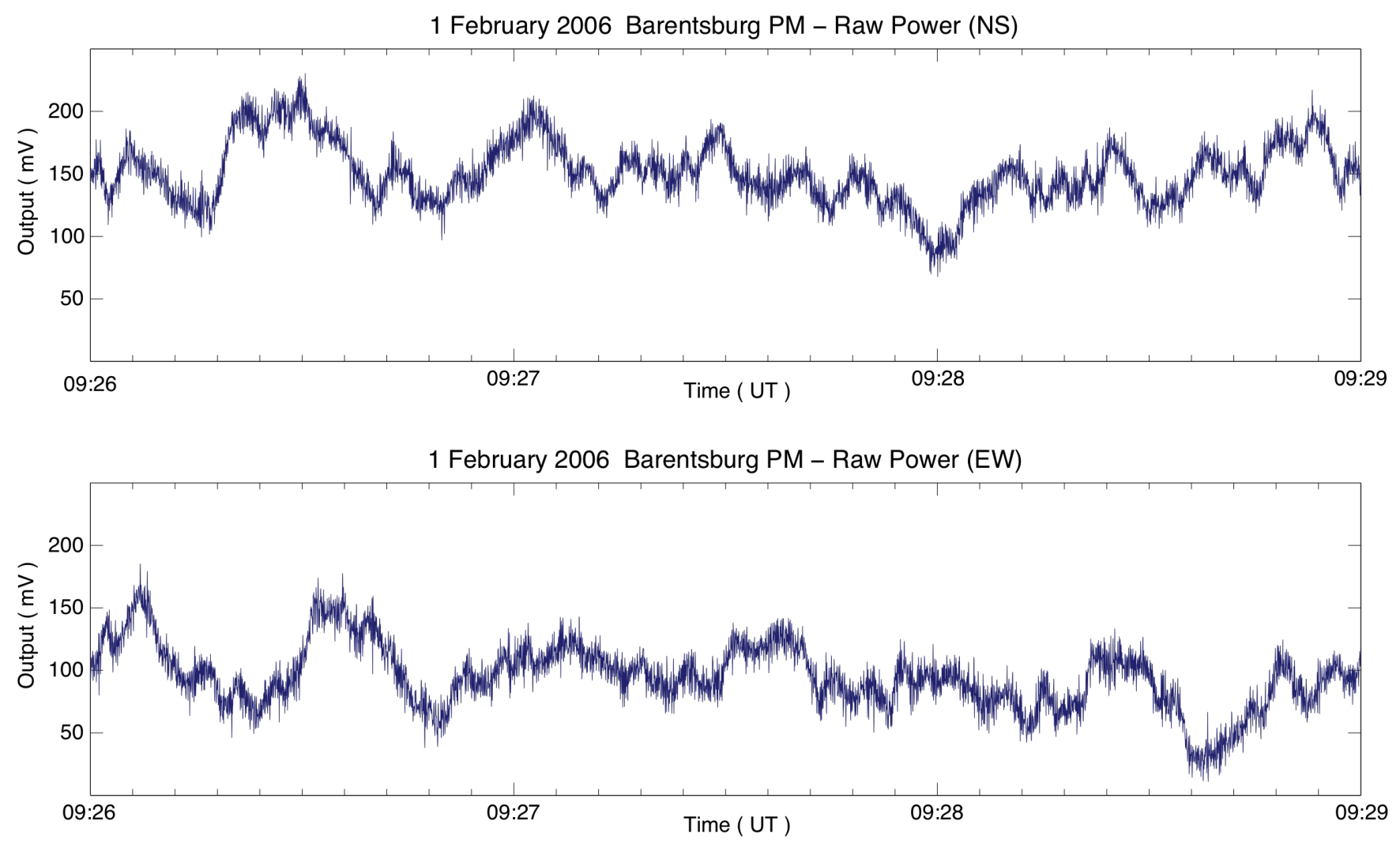

Fig. 9. Raw time domain output of the Barentsburg pulsation magnetometer. The upper panel is for the north-south inductor, the lower for the east-west.

time history from the reconnection of field lines within the two flux tubes (Lockwood et al., 1995). It should be noted that for the classical pulsating model (Lockwood and Smith, 1989), where cusp structures are caused by variations in the reconnection rate at the magnetopause, the convecting flux tubes originating from different reconnection pulses are also spatially separated. The difference in spatial cusp structures is that these spatial structures represent boundaries between, for example, convection cells (which can change position over time), while temporal structures are flux tubes convecting within a convection cell (Trattner et al., 2003). Furthermore, as the solar wind parameters did not vary dramatically, it is not expected that the observed step-down ion-dispersion is caused by change in the magnetosheath ion population.

The fact that the radar data show anti-correlation of the electron density between the $42 \mathrm{~m}$ and $32 \mathrm{~m}$ datasets, indicates that the ongoing processes above these two antennas are not related, meaning that we are not talking of structures with scale-sizes larger than $\sim 47 \mathrm{~km}$. Also, in the contrary to Pryse et al. (2000), who found that the ESR showed evidence of spatial signatures of increased electron temperatures within the region of ion-dispersion observed with DMSP14, we do not find any increased temperature despite the fact that the REIMEI trajectory is much closer to the radar volume than the DMSP14. Neither do we detect poleward moving events with the radar such as Lockwood et al. (1993a) did. Enhancements in both the electron density and the electron temperature are predicted signatures of pulsed reconnection in the ESR data (Davis and Lockwood, 1996). However, it should be mentioned that even for fully pulsed reconnection, the pulses may be difficult to detect if the radar is near the centre of the latitude range covered by the cusp ion precipitation and it could also be difficult to detect poleward moving events if the reconnection rate within the pulses is less than about twice the value between the pulses (Davis and Lockwood, 1996). It should also be kept in mind that during our observations, the convection speed was high $(750 \mathrm{~m} / \mathrm{s})$. Despite the fact that we did not observe any poleward moving events with the radar, it was clearly reflected in the magnetometer data. In view of the clear poleward moving ground magnetic impulse events and the poleward convection detected by SuperDARN we find that the lack of poleward moving forms in the ESR radar data must be due to the radar observation geometry (unfavourable). In a similar case, Lockwood et al. (1993a) documented clear poleward moving electron temperature events by the UHF antenna of the EISCAT Troms $\emptyset$ radar (better observations geometry). 
1 February 2006 IMAGE Magnetometer X-Component

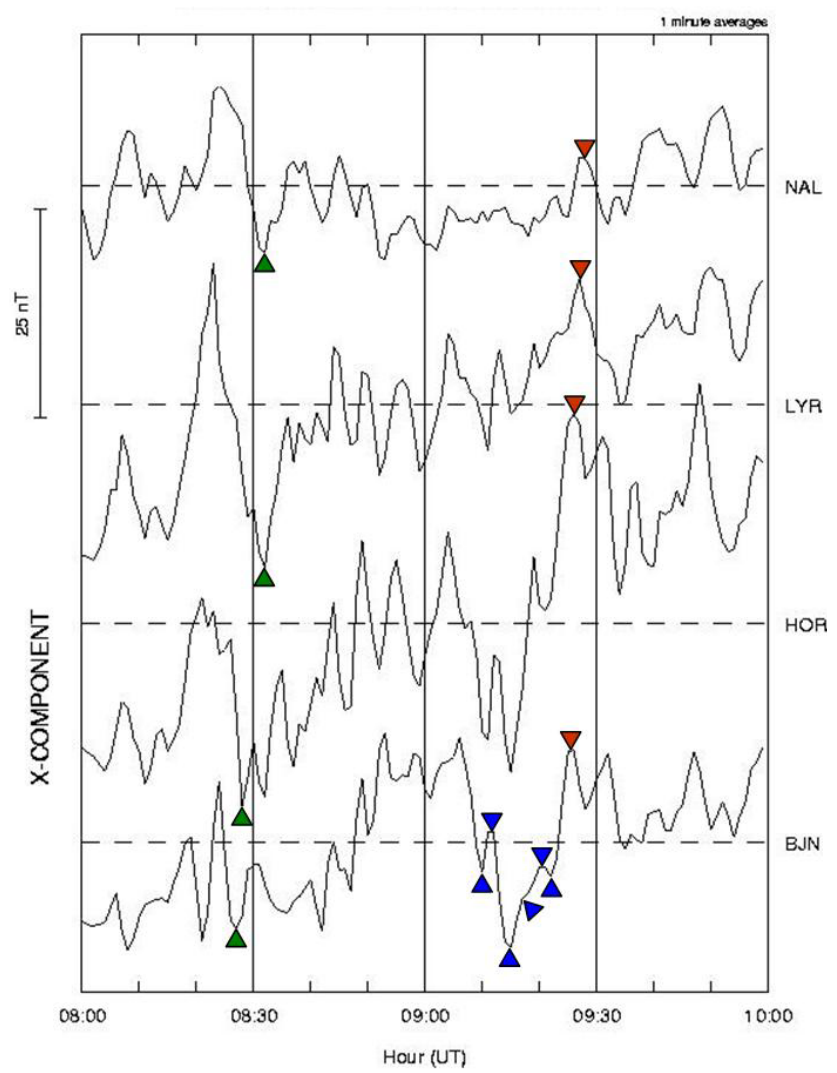

Fig. 10. Magnetogram for the X-component at 4 different stations from 08:00 UT to 10:00 UT: Bjørnøya (BJN, $71.57^{\circ} \mathrm{N} \mathrm{CGM),}$ Hornsund (HOR, 74.26 ${ }^{\circ} \mathrm{N}$ CGM), Longyearbyen (LYR, 75.38 $\mathrm{N}$ $\mathrm{CGM}$ ) and $\mathrm{Ny}$ Ålesund (NAL, 76.32 $\mathrm{N}$ CGM). Green triangles correspond to southward turning of IMF, blue triangles correspond to reconnection time of injected ions and red triangles show poleward propagation during the ongoing ion-dispersion.

Poleward moving convection structures in X-component magnetograms have regularly been reported in association with PMAFs (e.g. Øieroset et al., 1997; Sandholdt, 1997). Even the timing of injected ions seems to match with the observed X-component deflections in the magnetogram. This could be a coincidence, but most likely it is associated with pulsating reconnection. The recurrence time is comparable with previous results from Escoubet et al. (1992), who observed a corresponding step-down ion-dispersion. They found a recurrence time of 3 and $6 \mathrm{~min}$. These and our times are smaller than the average recurrence time $(\sim 8 \mathrm{~min})$ of FTEs observed at the magnetopause during southward IMF (Rijnbeek et al., 1984), indicating that our event is due to both rapid processes and small-scale features. Furthermore, the deflections at Bjørnøya (BJN), at $71^{\circ}$ MLAT, seem to belong to the category of Pc-5 pulsations. This is pulsations on closed field lines. The open/closed boundary is located at $\sim 75^{\circ}$ MLAT according to the satellite data. We note that the Pc-5 pulsations are expected on closed field lines adjacent to the newly open flux excited by FTEs, because, on immediately adjacent closed tubes, the switch on (and also the switch off) of the reconnection should give rise to standing damped Alfvén oscillations in the Pc-5 period band (Southwood, 1987). It should be noted that the poleward propagation speed $(3-4 \mathrm{~km} / \mathrm{s})$ of the magnetic reflections from the low-latitude station (BJN) to the high-latitude station (NAL) was about twice as high as the regular plasma flow. The deviation from the convection speed may not be very surprising. When comparison with the convection speed is made, one should be aware of the fact that the BJN ( $\left.71^{\circ} \mathrm{MLAT}\right)$ pulsations are a closed field line phenomenon which not necessarily matches the convection speed.

The appearance of temporal cusp steps depends on the satellite velocity relative to the convection velocity of the cusp structures. If the satellite crosses a boundary from a newly opened flux tube to an older one, it will encounter a decrease in the ion-energy-dispersion and vice versa. As REIMEI is a fast low-altitude satellite, it would most likely overtake the convection structure cusp. The convection speed observed by SuperDARN was about $750 \mathrm{~m} / \mathrm{s}$, which is much less than the satellite speeds. Consequently, REIMEI crossed from a "new" flux tube into an "older" one, and should then encounter a decrease in the cusp ion-energy-dispersion (Lockwood and Smith, 1989). This is consistent with the observations. The SuperDARN shows that the convection flow is poleward, moving away from the sun. Additionally, the REIMEI satellite is moving in the same direction as the convection and the ESR data show that the ion drift velocity is moving away from the $32 \mathrm{~m}$. The ion-dispersion in our case shows a step-down signature, represented by a decreasing ion-dispersion interrupted by three distinctive cusp steps, and two more, less distinctive. The ion-dispersion also shows the typical energy-latitude dispersion expected for southward IMF $\left(B_{z}<0\right)$, as the highest energy ions arrive at the lowest ILAT while the lower energy ions reach at higher ILAT (Onsager et al., 1993). The sudden decrease in the ion-energy-dispersion can be concurrent with the fact that REIMEI may have moved into neighbouring spatially separated flux tube or convection cell (Trattner et al., 2002a, b). In Fig. 7, we see that REIMEI is entering the dusk cell from south at about 09:27:15 UT, which is close to a major ion step and therefore could be a spatial structure. The later steps occur while REIMEI is overtaking successively older flux tubes within the same dusk-centred convection cell. They are therefore more likely to be temporal structures (sequences of reconnected flux tubes corresponding to discrete reconnection bursts).

The "flight" of magnetosheath ions towards the ionosphere caused by field-line merging is believed to also control characteristics of electron precipitation in the cusps. When a field line becomes open, then an ambi-polar field ties the much faster electrons to the following slower ions, preserving charge neutrality of the plasma. Electrons and 
ions hitting particles in the upper atmosphere then cause optical auroral forms that move poleward for southward IMF (PMAFs). Consequently such PMAFs observed with ground-based photometers have been associated with convecting field lines opened in reconnection pulses, similarly as the cusp ion steps (e.g. Sandholt et al., 2003a).

In our study, the variations of the electron energy spectra have been found to accompany the ion-dispersion. The main step of the ion-dispersion lasts for about $2100 \mathrm{~ms}$, and within this time, 4 main electron fluctuations occur. From the time of the first ion-step to the last one, the corresponding time from minimum to maximum in the electron spectra varied between 300-700 ms, and appear periodically with a frequency range between $0.5-0.8 \mathrm{~Hz}$. It is interesting to note that the steps in the ion-dispersion seem to correspond very well with the rapid fluctuation in the electron energy and flux. Whether it is a coincidence or not, will be a subject for further studies. It should be mentioned that one of the observed ion-steps (the 3rd one), is not well associated with rapid fluctuations in the electrons. Since this occur at the very same time as the ion flux increases, it is most likely due to the maintenance of quasi-neutrality of the plasma (Burch, 1985). However, this may explain why the electron flux decreases while the ion flux increases, but it does not necessarily explain the absence of fluctuations in the energy and why the electrons are less mobile during this time of interval.

The power spectrum $(0-2 \mathrm{~Hz})$ of the Finnish pulsation magnetometer shows activity around the time of the REIMEI overpass. It exhibits signatures of Pc-1 and Pc-3 pulsations in the period of interest. Our idea was to look for magnetic variations comparable with the electron fluctuations in the REIMEI data. Had we been able to see variations of $0.6-0.8 \mathrm{~Hz}$ also in the pulsation-magnetometer, it would then have favoured a temporal reconnection with scale size of $75 \mathrm{~km}$ or more. Generally, Pc-1 is associated with proton ion-cyclotron waves in the magnetospheric plasma caused by protons bouncing back and forth between the mirror points (Hargreaves, 1992); hence, the pulsations should not be related to the behaviour of the electrons. However, it should be noted that a possible origin of observed dayside Pc-1 magnetic pulsation at high latitudes (inside the polar cap) have been reported by Safargaleev et al. (2004). The IMF condition during their observations was a large negative $B_{z}$ component and a decreasing $B_{y}$ component down to almost zero, which resulted in reconfiguration of the large scale ionospheric convection. They concluded that the observed Pc1 pulsations were caused by ElectroMagnetic Ion Cyclotron (EMIC) instabilities of the anisotropic plasma from the magnetosheath penetrating into the dayside magnetosphere as a result of reconnection. In addition, high-latitude Pc-1 pulsations can also be associated with PMAFs (Kokubun et al., 1988). In our case we do not have a large negative $B_{z}$ component and neither a decreasing $B_{y}$ component. Pc-3 dayside pulsations are interpreted as magnetohydrodynamics (MHD) waves which correlate with the IMF conditions and they are observed over a wide range of latitudes (Hargreaves, 1992). A typical source is plasma instabilities in the upstream region of the near-Earth solar wind. Pc-3 can gain access to the ionosphere trough the cusp and a range of fluctuations in the auroral electron precipitation is possible. In addition, the periods of Pc-3 depends on the electron density: from this point of view, that type of micro-pulsation is more likely to influence the electron behaviour. The Pc-3 domain cannot be clearly identified in the total power spectrum, but it is possible to see some energy in the lower frequency domain. Finally, Pc-1 pulsations are often accompanied with trains of Pc-5 pulsations $(2-7 \mathrm{mHz})$ in the IMAGE network (Safargaleev et al., 2004). From this, Pc-5 reflects the behaviour of electrons and may be used to define the boundary of open/closed field lines (Ables et al., 1998). We do observe Pc-5 pulsations in the X-component from the IMAGE network above BJN, which together with the satellite data define the OCB. However, from the Barentsburg pulsation magnetometer, the Pc-1 pulsations were vague and the Pc-3 pulsations were far too slow, hence we believe that we are not dealing with large-scale structures $(>75 \mathrm{~km})$.

Su et al. (2001) did a study which also included the electron structures, where they found burst-like precipitating electrons in the FAST data. They conclude that the highly irregular electrons in the cusp were associated with the smallscale electric field fluctuations, which are again associated with propagating Alfvén waves (Chaston et al., 1999). Upward electron beams are occasionally observed in the cusp region, but such events are rare. In our study we see both upward and downward electrons, but they are not particularly of the burst-type. Hence our case study differs from that particular case.

Our REIMEI EISA data now reveal a considerably finer structure in the electron precipitation than found in the ions. What is the cause of this substructure? Density measurements by the ESR do not give many clues about the spatial and/or temporal nature of the variations seen by the REIMEI EISA. However, this is most likely due to the insufficient resolutions of the radar data and noise. Similarly, groundbased photometers have probably not been able to resolve such fast $(\sim 1 \mathrm{~s})$ and/or narrow $(\sim 1 \mathrm{~km})$ structures, and we may observe here a so far unnoticed but frequent feature of cusp precipitation. Quite likely also the field-aligned current varies with the electrons flux. Unfortunately, the REIMEI magnetometer is only for attitude control and has a very low sampling rate, and the ground-based magnetometers are not sensitive to small-scale ionospheric currents, but show only larger current systems. Small-scale intense field-aligned current variations have been seen frequently in the cusp with the CHAMP satellite at about $420 \mathrm{~km}$ altitude (Rother et al., 2007), and Farrugia et al. (2004) have documented mesoscale FAC structures associated with the stepped cusp.

At the dayside magnetopause, relatively small-scale structures, such as thin currents etc, have been found in several recent works (André et al., 2004; Vaivads et al. 2007). A 
possible explanation for our observations is that the electron flux on open field lines gets modulated over relatively small "ion-scales" when magnetic reconnection rates change in time. This then causes both the ion step energy and the rapid variations in the electron precipitation at ionospheric heights. The modulation of the electron precipitation, when mapped back to the suspected location of reconnection occurs, on similar scales as the Alfvén waves which have been observed near an X-line in the magnetopause (Chaston et al., 2005).

\section{Summary}

We have demonstrated that the majority of our observed cusp structured ion-dispersion is most likely related to a magnetopause reconnection, produced in an intermittent state by temporal cusp features rather than a stationary one. This is in particular consistent with the poleward moving impulse events seen in the ground-based IMAGE data. The associated electron fluctuations we believe have been modulated over relatively small "ion-scales" when magnetic reconnection rates change in time. The fact that we do not see clear Pc1 events in the pulsating magnetometer, an anti-correlation in the electron density between the $32 \mathrm{~m}$ - and $42 \mathrm{~m}$ antenna and a short recurrence time in the reconnection, indicates a small-scale structure, less than $5 \mathrm{~km}$. Finally, in our event, the time between each ion-step is small, but the fluctuation in both the electron energy and flux is far more rapid $(<1 \mathrm{~s})$. This small-scale and fast electron fluctuation is most likely also due to the reconnection process as indicated above, but exactly how it occurs may deserve a closer investigation.

Acknowledgements. The authors acknowledge the Japanese smallsatellite mission team for providing REIMEI data, the international facility EISCAT for supplying radar data, the Sodankylä Geophysical Observatory (Finland) for distributing the IMAGE and pulsation magnetometer data and the SuperDARN team for access to convection data. We are grateful to M. Förster and C. L. Hoz for useful discussions. Thanks to U. P. Løvhaug and T. L. Hansen for comments on this paper.

Topical Editor K. Kauristie thanks S. Massetti and another anonymous referee for their help in evaluating this paper.

\section{References}

Ables, S. I., Fraser, B. J., Waters, C. L., and Neudegg, D. A.: Monitoring cusp/cleft topology using Pc5 ULF waves, Geophys. Res. Lett., 25, 1507-1510, 1998.

André, M., Vaivads, A., Buchert, S. C., Fazakerley, A. N., and Lahiff, A.: Thin electron-scale layers at the magnetopause, Geophys. Res. Lett., 31, L03803, doi:10.1029/2003GL018137, 2004.

Burch, J. L.: Quasi-neutrality in the polar cusp, Geophys. Res. Lett., 12, 469-472, 1985.

Chaston, C. C., Carlson, C. W., Peria, W. J., Ergun, R. E., and McFadden, J. P.: FAST observations of internal Alfven waves in the dayside aurora, Geophys. Res. Lett., 26, 647-650, 1999.
Chaston, C. C., Phan, T. D., Bonnell, J. W., Mozer, F. S., Acuña, M., Goldstein, M. L., Balogh, A., Andre, M., Reme, H., and Fazakerley, A.: Drift-Kinetic Alfvén Waves Observed near a Reconnection X Line in the Earth's Magnetopause, Phys. Rev. Lett., 95, 065002, doi:10.1103/PhysRevLett.95.065002, 2005.

Chen, J. and Fritz, T. A.: High-altitude cusp: the extremely dynamic region in geospace, Surv. Geophys., 26, 71-93, 2005.

Cowley, S. W. H. and Lockwood, M.: Excitation and decay of solar wind-driven flows in the magnetosphere-ionosphere system, Ann. Geophys., 10, 103-115, 1992, http://www.ann-geophys.net/10/103/1992/.

Cowley, S. W. H., Freeman, M. P., Lockwood, M., and Smith, M. F.: The ionospheric signatures of flux transfer events, in CLUSTER: Dayside Polar Cusp, edited by Barron, C. I., European Space Agency Spec. Publ., ESA SP-330, 105, 1991.

Davis, C. J. and Lockwood, M.: Predicted signatures of pulsed reconnection in ESR data, Ann. Geophys., 14, 1246-1256, 1996, http://www.ann-geophys.net/14/1246/1996/.

Escoubet, C. P., Smith, M. F., Fung, S. F., Anderson, P. C., Hoffman, R. A., Basinska, E. M., and Bosqued, J. M.: Staircase Ion Signature in the Polar Cusp: A Case Study, Geophys. Res. Lett., 19, 1735-1738, 1992.

Escoubet, C. P., Bosqued, J. M., Berchem, J., Trattner, K. J., Taylor, M. G. G. T., Pitout, F., Laakso, H., Masson, A., Dunlop, M., Reme, H., Dandouras, I., and Fazakerley, A.: Temporal evolution of a staircase ion signature observed by Cluster in the mid-altitude polar cusp, Geophys. Res. Lett., 33, L07108, doi:1029/2005GL025598, 2006.

Farrugia, C. J., Rijnbeek, R. P., Saunders, M. A., Southwood, D. J., Rodgers, D. J.., Smith, M. F., Chaloner, C. P., Hall, D. S., Christiansen, P. J., and Woolliscroft, L. J. C.: A multi-instrument study of flux transfer event structure, J. Geophys. Res., 93, 14 46514477, 1988.

Farrugia, C. J., Sandholt, P. E., Denig, W. F., and Torbert, R. B.: Observations of a correspondence between poleward moving auroral forms and stepped cusp ion precipitation, J. Geophys. Res., 103, 9309-9315, 1998.

Farrugia, C. J., Sandholt, P. E., Torbert, R. B., and Østgaard, N.: Temporal and spatial aspects of the cusp inferred from local and global ground- and space-based observations in a case study, J. Geophys, Res., 109, A04209, doi:10.1029/2003JA010121, 2004.

Frank, L. A.: Plasma in the Earth's Polar Magnetosphere, J. Geophys. Res., 76, 5202-5219, 1971.

Frank, L. A. and Ackerson, K. L.: Observations of charged particle precipitation into the auroral zone, J. Geophys. Res., 76, 36123643, 1971.

Hargreaves, J. K.: The solar-terrestrial environment, Cambridge university press, Great Britain, 1992.

Heikkila, W. J.: Penetration of particles into the polar cap and auroral regions, in: Critical Problems of Magnetospheric Physics, edited by: Dyer, E. R., p. 67, National Academy of Science, Washington, D.C., 1972.

Heikkila, W. J. and Winningham, J. D.: Penetration of Magnetosheath Plasma to Low Altitudes through the dayside magnetospheric cusps, J. Geophys. Res., 76, 883-891, 1971.

Kokubun, S., Yamamoto, T., Hayashi, K., Oguti, T., and Egeland, A.: Impulsive Pi bursts associated with poleward moving auroras near the polar cusp, J. Geomag. Geoelectr., 40, 537-551, 1988.

Lockwood, M.: Ionospheric signatures of pulsed magnetopause re- 
connection, in: Physical signatures of magnetopause boundary layer Processes, edited by: Holtet, J. A. and Egeland, A., NATO ASI Series C, 425, 229-243, 1994.

Lockwood, M. and Davis, C. J.: Occurrence Probability, Width and Number of Steps of Cusp Precipitation for Fully Pulsed Reconnection at the Dayside Magnetopause, J. Geophys. Res., 100, 7627-7640, 1995.

Lockwood, M. and Davis, C. J.: On the longitudinal extent of magnetopause reconnection pulses, Ann. Geophys., 14, 865-878, 1996 , http://www.ann-geophys.net/14/865/1996/.

Lockwood, M. and Smith, M. F.: Low-altitude Signatures of the Cusp and Flux Transfer Events, Geophys. Res. Lett., 16, 879$882,1989$.

Lockwood, M. and Smith, M. F.: Reply to comment by P. T. Newell on "Low-altitude signatures of the cusp and flux transfer events" by M. Lockwood and M. F. Smith, Geophys. Res. Lett., 17, 305306, 1990 .

Lockwood, M. and Smith, M. F.: The Variation of Reconnection Rate at the Dayside magnetopause and cusp Ion precipitation, J. Geophys. Res., 97, 14 841-14 847, 1992.

Lockwood, M. and Smith, M. F.: Low and Middle Altitude Cusp Particle Signatures for General Magnetopause Reconnection Rate Variations: 1. Theory, J. Geophys. Res., 99, 85318553, 1994.

Lockwood, M., Denig, W. F., Farmer, A. D., Davda, V. N., Cowley, S. W. H., and Lühr, H.: Ionospheric signatures of pulsed reconnection at the Earth's magnetopause, Nature, 361, 424-427, 1993a.

Lockwood, M., Moen, J., Cowley, S. W. H., Farmer, A. D., Løvhaug, U. P., Lühr, H., and Davda, V. N.: Variability of dayside convection and motions of the dayside cusp/cleft aurora, Geophys. Res. Lett., 20, 1011-1014, 1993b.

Lockwood, M., Davis, C. J., Smith., M. F., Onsager, T. G., and Denig, W. F., Location and characteristics of the reconnection $\mathrm{X}$ line deduced from low-altitude satellite and ground-based observations 2. Defense Meteorological Satellite Program and European Incoherent Scatter data, J. Geophys. Res., 100, 21803 $21813,1995$.

Lockwood, M., Davis, C. J., Onsager, T. G., and Scudder, J. D.: Modelling signatures of pulsed magnetopause reconnection in cusp ion dispersion signatures seen at middle altitudes, Geophys. Res. Lett., 25, 591-594, 1998.

Lockwood, M., Milan, S. E., Onsager, T., Perry, C. H., Scudder, J. A., Russel, C. T., and Brittnacher, M.: Cusp ion steps, fieldaligned currents and poleward moving auroral forms, J. Geophys. Res., 106, 29555-29569, 2001.

Matsuoka, A., Tsuruda, K., Hayakawa, H., Mukai, T., Nishida, A., Okada, T., Kaya, N., and Fukunishi, H.: Electric Field Fluctuations and Charged Particle Precipitation in the Cusp, J. Geophys. Res., 98, 11 225-11 234, 1993.

Morley, S. K. and Lockwood, M.: The dependence of cusp ion signatures on the reconnection rate, Ann. Geophys., 21, 947-953, 2003, http://www.ann-geophys.net/21/947/2003/.

Newell, P. T. and Meng, C.-I.: The Cusp and the Cleft/Boundary Layer: Low-Altitude Identification and Statistical Local Time Variation, J. Geophys. Res., 93, 14 549-14 556, 1988.

Newell, P. T. and Meng, C.-I.: Ion acceleration at the equatorward edge of the cusp: low-altitude observations of patchy merging, Geophys. Res. Lett., 18, 1829-1832, 1991.

Newell, P. T. and Sibeck, D. G.: Upper Limits on the Contribution of Flux Transfer Events to Ionospheric Convection, Geophys. Res. Lett., 20, 2829-2832, 1993.

Newell, P. T., Wing, S., and Meng, C.-I.: Spectral properties and source regions of dayside electron acceleration events, J. Geophys. Res., 110, A11205, doi:10.1029/2005JA011264, 2005.

Ohtani, S., Blomberg, L. G., Newell, P. T., Yamauchi, M., Potemra, T. A., and Zanetti, L. J.: Altitude comparison of dayside field-aligned current signatures by Viking and DMSPF7: Intermediate-scale field-aligned current systems, J. Geophys. Res., 101, 15 297-15 310, 1996.

Onsager, T. G., Kletzing, C. A., Austin, J. B., and MacKiernan, H.: Model of magnetosheath plasma in the magnetosphere: Cusp and mantle particles at low-altitudes, Geophys. Res. Lett., 20, 479482, 1993.

Onsager, T. G., Chang, S.-W., Perez, J. D., Austin, J. B., and Janoo, L. X.: Low-altitude observations and modelling of quasi-steady magnetopause reconnection, J. Geophys. Res., 100, 11831 $11843,1995$.

Phillips, J. L., Bame, S. J., Elphic, R. C., Gosling, J. T., Thomsen, M. F., and Onsager, T. G.: Well-Resolved Observations by ISEE 2 of Ion Dispersion in the Magnetospheric Cusp, J. Geophys. Res., 98, 13 429-13 440, 1993.

Pinnock, M., Rodger, A. S., Dudeney, J. R., Rich, F., and Baker, K. B.: High spatial and temporal resolution observations of the ionospheric cusp, Ann. Geophys., 13, 919-925, 1995, http://www.ann-geophys.net/13/919/1995/.

Pryse, S. E., Smith, A. M., Walker, I. K., and Kersley, L.: Multiinstrument study of footprints of magnetopause reconnection in the summer ionosphere, Ann. Geophys., 18, 1118-1127, 2000, http://www.ann-geophys.net/18/1118/2000/.

Reiff, P. H., Hill, T. W., and Burch, J. L.: Solar Wind Plasma Injection at the Dayside Magnetospheric Cusp, J. Geophys. Res., 82, 479-491, 1977.

Rijnbeek, R. P., Cowley, S. W. H., Southwood, D. J., and Russel, C. T.: A survey of dayside flux transfer events observed by the ISEE 1 and 2 magnetometers, J. Geophys. Res., 89, 786-800, 1984.

Rosenbauer, H., Grünwaldt, H., Montgomery, M. D., Paschmann, G., and Sckopke, N.: Heos 2 Plasma Observations in the Distant Polar Magnetosphere: The Plasma Mantle, J. Geophys. Res., 80, 2723-2737, 1975.

Rother, M., Schlegel, K., and Lühr, H.: CHAMP observation of intense kilometer-scale field-aligned currents, evidence for an ionospheric Alfvén resonator, Ann. Geophys., 25, 1603-1615, 2007 , http://www.ann-geophys.net/25/1603/2007/.

Russel, C. T. and Elphic, R. C.: ISEE observations of flux transfer events at the dayside magnetopause, J. Geophys. Res. Lett., 6, 33-36, 1978.

Safargaleev, V., Serebryanskaya, Koustov, A., Lester, M., Pchelkina, E., and Vasilyev, A.: A possible origin of dayside Pc1 magnetic pulsations observed at high latitudes, Ann. Geophys., 22, 2997-3008, 2004, http://www.ann-geophys.net/22/2997/2004/.

Sandholt, P. E.: Dayside Polar CUSP/Cleft Aurora: Morphology and Dynamics, Phys. Chem. Earth, 22, 675-684, 1997.

Sandholt, P. E. and Farrugia, C. J.: Poleward moving auroral forms 
(PMAFs) revisited: responses of aurorae, plasma convection and Birkeland currents in the pre- and postnoon sectors under positive and negative IMF $B_{y}$ conditions, Ann. Geophys., 25, 16291652, 2007, http://www.ann-geophys.net/25/1629/2007/.

Sandholt, P. E., Farrugia, C. J., Denig, W. F., Cowley, S. W. H., and Lester, M.: Spontaneous and driven cusp dynamics: Optical aurora, particle precipitation, and plasma convection, Planet. Space Sci., 51, 797-812, 2003a.

Sandholt, P. E., Moen, J., Farrugia, C. J., Cowley, S. W. H., Lester, M., Milan, S. E., Valladares, C., Denig, W. F., and Eriksson, S.: Multi-site observations of the association between aurora and plasma convection in the cusp/polar cap during a southeastward (By $\simeq|B z|)$ IMF orientation, Ann. Geophys., 21, 539-558, 2003b, http://www.ann-geophys.net/21/539/2003/.

Shelley, E. G., Sharp, R. D., and Johnson, R. G.: $\mathrm{He}^{++}$and $\mathrm{H}^{+}$ Flux Measurements in the Dayside Cusp, J. Geophys. Res., 81, 2363-2370, 1976.

Smith, M. F. and Lockwood, M.: The pulsating cusp, Geophys. Res. Lett., 17, 1069-1072, 1990.

Smith, M. F. and Lockwood, M.: Earth's magnetospheric cusps, Rev. Geophys, 34, 233-260, 1996.

Smith, E. J., Lockwood, M., and Cowley, S. W. H.: The statistical cusp: The flux transfer event model, Planet. Space Sci., 40, 1251-1268, 1992.

Southwood, D. J.: The ionospheric signatures of flux transfer events, J. Geophys. Res., 92, 3207-3213, 1987.

Su, Y.-J., Ergun, R. E., Peterson, W. K., Onsager, T. G., Pfaff, R., Carlson, C. W., and Strangeway, R. J.: Fast Auroral Snapshot observations of cusp electron and ion structures, J. Geophys. Res., 106, 25 595-25 600, 2001.

Trattner, K. J., Fuselier, S. A., Peterson, W. K., Sauvaud, J.-A., Stenuit, H., Dubouloz, N., and Kovrazhkin, R. A.: On spatial and temporal structures in the cusp, J. Geophys. Res., 104, $28411-$ $28421,1999$.

Trattner, K. J., Fuselier, S. A., Peterson, W. K., Boehm, M., Klumpar, D., Carlson, C. W., and Yeoman, T. K.: Temporal versus spatial interpretation of cusp ion structures observed by two spacecraft, J. Geophys. Res., 107, 1287, doi:10.1029/2001JA000181, 2002a.

Trattner, K. J., Fuselier, S. A., Peterson, W. K., and Carlson, C. W.: Spatial features observed in the cusp under steady solar wind conditions, J. Geophys. Res., 107, 1288, doi:10.1029/2001JA000262, 2002b.
Trattner, K. J., Fuselier, S. A., Yeoman, T. K., Korth, A., Fraenz, M., Mouikis, C., Kucharek, H., Kistler, L. M., Escoubet, C. P., Rème, H., Dandouras, I., Sauvaud, J. A., Bosqued, J. M., Klecker, B., Carlson, C., Phan, T., McFadden, J. P., Amata, E., and Eliasson, L.: Cusp structures: combining multi-spacecraft observations with ground-based observations, Ann. Geophys., 21, 20312041, 2003, http://www.ann-geophys.net/21/2031/2003/.

Trattner, K. J., Fuselier, S. A., Yeoman, T. K., Carlson, C. W., Peterson, W. K., Korth, A., Reme, H., Sauvaud, J. A., and Dubouloz, N.: Spatial and temporal cusp structures observed by multiple spacecraft and ground based observation, Surv. Geophys., 26, 281-305, 2005.

Vaivads, A., Santolik, O., Stenberg, G., André, M., Owen, C. J., Canu, P., and Dunlop, M.: Source of whistler emissions at the dayside magnetopause, Geophys. Res. Lett, 34, L09106, doi:10.1029/2006GL029195, 2007.

Wannberg, G., Wolf, I., Vanhainen, L.-G., Koskenniemi, K., Röttger, J., Postila, M., Markkanen, J., Jacobsen, R., Stenberg, A., Larsen, R., Eliassen, S., Heck, S., and Huuskonen, A.: The EISCAT svalbard radar: A case study in modern incoherent scatter radar system design, Radio Sci., 32, 2283-2307, 1997.

Weimer, D. R.: Ober, D. M., Maynard, N. C., Bruke, W. J., Collier, M. R., McComas, D. J., Ness, N. F., and Smith, C. W.: Variable time delays in the propagation of the interplanetary magnetic field, J. Geophys. Res., 107, 1210, doi:10.1029/2001JA009102, 2002.

Weiss, L. A., Reiff, P. H., Weber, E. J., Carlson, H. C., Lockwood, M., and Peterson, W. K.: Flow-Aligned Jets in the Magnetospheric Cusp: Results from the Geospace Environment Modeling Pilot Program, J. Geophys. Res., 100, 7649-7659, 1995.

Wing, S., Newell, P. T., and Rouhoniemi, J. M.: Double Cusp: Model prediction and observational verification, J. Geophys. Res., 106, 25 571-25 593, 2001.

Zhou, X. W., Russel, C. T., Le, G., Fuselier, S. A., and Scudder, J. D.: Solar wind control of the polar cusp at high altitude, J. Geophys. Res., 105, 245-251, 2000.

Øieroset, M., Sandholt, P. E., Lühr, H., Denig, W. F., and Moretto, T.: Auroral and geomagnetic events at cusp/mantle latitudes in the prenoon sector during positive IMF $\mathrm{B}_{y}$ conditions: Signatures of pulsed magnetopause reconnection, J. Geophys. Res., 102, 7191-7205, 1997. 